\title{
EJERCIENDO LA JUSTICIA FUERA DE LOS TRIBUNALES: \\ DE LAS REIVINDICACIONES \\ DECIMONÓNICAS A LAS RESTITUCIONES \\ DE LA REFORMA AGRARIA
}

\author{
Helga Baitenmann \\ University of London ${ }^{1}$
}

INTRODUCCIÓN

\begin{abstract}
Sabemos que a lo largo del siglo xix los representantes de Slos pueblos utilizaron activamente las diversas instancias judiciales (litigios, juicios y amparos) para tratar de resolver sus disputas por las tierras entre pueblos, y entre pueblos y particulares. ${ }^{2}$ Sin embargo, estos procesos siempre fueron
\end{abstract}

Fecha de recepción: 3 de mayo de 2016

Fecha de aceptación: 20 de agosto de 2016

${ }^{1}$ Quisiera agradecer la invaluable asistencia de la licenciada Beatriz Montes Rojas y de los pasantes de la licenciatura en historia de la Universidad Nacional Autónoma de México, Diego Marañón Henríquez y Karen Verdejo Ramírez, así como las correcciones de estilo del maestro Josué Gerardo Ochoa Fragoso. Este artículo se basa en algunas secciones del manuscrito titulado "Matters of Justice: Agrarian Reform and the Judiciary in Revolutionary Mexico". Agradezco infinitamente las múltiples conversaciones con Emilio Kourí sobre este proyecto.

2 FALCón, "El arte de la petición”, presenta una versión más pesimista, Knowlton, "Tribunales federales" y Fenner, "Pérdida o permanencia", 
costosos y tardados. Además, los apoderados de los pueblos tuvieron una incierta capacidad legal para realizar actos jurídicos sobre su propiedad colectiva, por lo que muchos decidían presionar al Poder Ejecutivo (funcionarios municipales, jefes políticos, gobernadores, titulares de las Secretarías de Fomento, Hacienda y Justicia, y hasta al mismo presidente) para que resolviera estas querellas administrativamente. Los funcionarios de este poder podían practicar diferentes formas de mediación y arbitraje, y en algunos estados expedían (o no) permisos para litigar. Sin embargo, a lo largo del siglo xIx, los juzgados y la Suprema Corte defendieron exitosamente su jurisdicción sobre los asuntos contenciosos, incluyendo los juicios de reivindicación y los de apeo y deslinde de las tierras de los pueblos.

Durante los años maderistas, la Secretaría de Fomento continuó la política de desamortización como una manera de resolver las querellas por las tierras comunales, prometiendo solucionar los conflictos "dentro de su esfera de

presentan una perspectiva más favorable del acceso a la administración de la justicia por parte de los pueblos. Uso el término "pueblo" indistintamente para toda población indígena o multiétnica que haya tenido en algún momento de su historia (o que sus pobladores creyeran haber tenido) terrenos comunales. Para un análisis del concepto de pueblo, véase KouRí, "Los pueblos y sus tierras", pp. 266-274. Con el material de archivo obtenido para este artículo es difícil precisar quiénes eran los representantes de los pueblos y a quiénes representaban. Los apoderados podían ser funcionarios del ayuntamiento, autoridades tradicionales u otro tipo de representación con cierta legitimidad. En ocasiones, representaban sólo al grupo más afectado por la usurpación, a los más pudientes o a una facción que aprovechaba las leyes para beneficio propio. Muchas veces los apoderados eran abogados. Otras, eran los llamados "tinterillos" quienes, a pesar de no tener acreditación, vivían de promover juicios. Véase también FaLcón, "El arte de la petición”, pp. 477-478. 
acción administrativa". ${ }^{3}$ Decenas de apoderados de los pueblos vieron en esta política agraria una oportunidad para resolver sus conflictos fuera de los tribunales. Sin embargo, Francisco I. Madero no tenía la intención de invadir la esfera judicial. Más aún, muchos propietarios impugnaron los apeos y deslindes promovidos por Fomento y solicitaron protección de la justicia federal. Al defender los derechos de propiedad privada inscritos en la Constitución de 1857, la Suprema Corte invalidó todo intento por parte de la Secretaría de Fomento de mediar en los conflictos por las tierras de los pueblos.

Después del asesinato de Madero, Venustiano Carranza desconoció al Poder Judicial y no lo reestableció sino hasta 1917. En este ínterin firmó una ley agraria que permitió al Ejecutivo ejercer la justicia fuera de los tribunales, al transformar los juicios reivindicativos y de apeo y deslinde en restituciones agrarias (las cuales, cuando no se podían justificar, se convertían en "dotaciones"). Lo que en su momento fue una ley provisional, expedida por Carranza en uso de facultades extraordinarias durante una guerra civil en la cual el país no tenía un Poder Judicial federal, fue incorporada por los constituyentes de 1916-1917 al nuevo artículo 27. Más aún, la nueva Suprema Corte, electa el 1ํㅡㄹ de mayo de 1917 por el Congreso, participó incondicionalmente en la ampliación de la jurisdicción del Ejecutivo, cediéndole a éste una serie de prerrogativas que constitucionalmente le pertenecían. El resultado fue, según el magistrado Sergio García Ramírez, que "en el Ejecutivo se reunirían, por voluntad

${ }^{3}$ Circular del 17 de febrero de 1912, en Colección de leyes sobre tierras, p. 174. 
de una historia imperiosa, los poderes que regularmente se hallan separados", concediéndole al Ejecutivo "facultades metaconstitucionales". ${ }^{4}$

Esta perspectiva de la reforma agraria como un reajuste de las facultades y competencias entre los poderes Ejecutivo y Judicial nos permite revalorar las ideas dominantes sobre el momento fundacional del derecho agrario y los orígenes del autoritarismo presidencial mexicano del siglo xx.

\section{LA RESOLUCIÓN DE LOS CONFLICTOS POR TIERRAS}

EN EL SIGLO XIX

Durante la colonia, cuando los litigantes indígenas buscaban reclamar la usurpación de sus tierras acudían al Juzgado General de Indios. Allí, nos dice Woodrow Borah, estaban "sujetos a una protección legal especial", los procedimientos eran sumarios y rápidos, y los gastos legales, reducidos o nulos. ${ }^{5}$ Cuando la Constitución de 1824 convirtió a la nación en una república federal con tres poderes (el Legislativo, el Ejecutivo y el Judicial), los legisladores debatieron si la reivindicación de las tierras de los pueblos sería una cuestión administrativa o judicial. Por lo tanto, en el Congreso Constituyente del Estado de México (que en aquel entonces incluía los estados de Morelos, Hidalgo y Guerrero), el diputado José María Jáuregui señaló que "estaban confundidos desde tiempo de los virreyes las providencias gubernativas y judiciales, con motivo de residir en ellos todos los poderes mezclados"; pero ahora

${ }^{4}$ García Ramírez, "Establecimiento y horizonte", p. 35.

${ }^{5}$ Borah, "La justificación del juzgado”, p. 147. 
había que respetar "la línea divisoria que tan justamente ha tirado entre los poderes". ${ }^{6}$

Los demás estados también respetaron estas líneas divisorias. En Jalisco, por ejemplo, ya para 1925 quedaba claro que los juicios de reivindicación de tierras tenían que ser oídos por los tribunales de justicia. Por ejemplo, cuando los indígenas del pueblo de San Gabriel demandaron ante el Senado de Jalisco a la dueña de la hacienda Guadalupe por haber usurpado terrenos de su fundo legal, los senadores decidieron que no podían resolver el expediente "por pertenecer su conocimiento a los tribunales de justicia". 7 De nuevo, después de caer la república centralista en la cual el país estuvo organizado bajo un régimen unitario, el Consejo Estatal de Jalisco le informó al gobernador que los indígenas del pueblo de Jalisco se quejaban de haber sido despojados de un cerco de su propiedad por el alcalde y pedían su restitución. El consejo opinó que "la resolución que en ellos debe recaer, es del resorte del Poder Judicial, por cuya vía pueden los interesados, si les conviene, deducir sus derechos". ${ }^{8}$

Las controversias jurídicas entre pueblos o entre pueblos y propietarios eran responsabilidad de los Juzgados de Primera Instancia del Poder Judicial estatal. En estos litigios, la carga de la prueba recaía sobre el demandante, quien debía

${ }^{6}$ Actas del Congreso del Estado Libre de México, p. 102 (1º de abril de 1824). Véase también Birrichaga, “Administración de tierras”, pp. 176-177. Para no discriminar entre los letrados y los iletrados, y para no confundir la gramática antigua con los errores de los copistas de la época, todas las citas aparecen con reglas ortográficas actuales.

7 Colección de acuerdos, órdenes y decretos, vol. 1, p. 28 (19 de septiembre de 1925).

${ }^{8}$ Colección de acuerdos, órdenes y decretos, vol. 1, p. 83 (22 de enero de 1849). 
demostrar su derecho de propiedad y así desvirtuar los derechos de posesión del demandado. Por ejemplo, cuando en 1849 el representante de San Vicente Chimalhuacán Chalco demandó al pueblo de Santiago Mamalhuazucan, el juez civil de Chalco explicó que

[...] para el interdicto de despojo de bienes raíces y especialmente de tierras, no bastaba acreditar la usurpación y tenencia actual de parte del despojante, fijando los rumbos y linderos, sino también la posesión anterior, con título justo y buena fe, de parte del despojado, señalando además el año y mes en que lo habían sido, todo conforme a las leyes que se citan. ${ }^{9}$

En la mayoría de los casos, la carga de la prueba del demandante en los juicios de reivindicación fue casi imposible de cumplir por una serie de razones. Primero, como lo explica Daniela Marino, las ideas liberales sobre la propiedad absoluta con títulos perfectos chocaban con una realidad en la que había una pluralidad jurídica de formas propietarias (individual, colectiva, amortizada, de dominio directo y de derechos reales y servidumbres) y una diversidad de títulos de acceso a la tierra. ${ }^{10}$ Por lo tanto, lo que los líderes llamaban "títulos primordiales" muchas veces eran lo que Luis Arrioja llama "un corpus documental [...] que -a diferencia de los títulos primordiales de la etapa colonial-

9 AGA, San Vicente Chimalhuacán, Ozumba, Estado de México, exp. 24/12024, leg. 3, f. 155.

${ }^{10}$ Marino, "La fuerza de la ley", pp. 207-208; Daniela Marino, "18561915: ¿Revolución de la propiedad en México?”, ponencia presentada en la XII Reunión de Historiadores de México, Estados Unidos y Canadá del 26 al 30 de octubre de 2010, Santiago de Querétaro, pp. 4-5. 
se integraba con mercedes, actas de congregación, composiciones, testamentos, registro de compraventa de tierras, vistas de ojos, mapas de linderos, entre otras cosas”. ${ }^{11}$ Más aún, los títulos de propiedad no incluían los usos y costumbres de los pueblos, de los productos de los montes (como leña y carbón), de los pastizales (para la alimentación de sus animales), de los ríos y lagos (para la pesca y la caza de pájaros) ni del derecho de servidumbre (como el camino de acceso en tierras privadas). ${ }^{12}$ Segundo, muchos pueblos nunca tuvieron títulos, ya que fueron fundados en terrenos de caciques indios o se formaron como barrios de las cabeceras. ${ }^{13}$ Tercero, aun cuando los pueblos preservaran sus títulos coloniales, éstos eran descriptivos y demasiado ambiguos para establecer con exactitud los linderos de las tierras de los pueblos. ${ }^{14}$ Más aún, muchos títulos son copias con falsificaciones o con errores de los copistas, no sólo de la época sino también antiguos. ${ }^{15}$

Aun en aquellos casos en que los pueblos tenían títulos coloniales auténticos con linderos identificables, la impartición de justicia siempre fue costosa y dilatada. ${ }^{16}$ En Puebla, por ejemplo, el alcalde, los principales y los vecinos de Trinidad Tepango comparecieron ante el ministro de Gober-

11 Arrioja, “Conflictos por tierras”, pp. 194-195. Véase también HerNÁNDEZ, Anenecuilco.

12 Molina Enríquez, Los grandes problemas, p. 126.

13 Holden, "Priorities of the State", p. 603.

14 Marino, "La modernidad a juicio”, p. 323.

15 Romero Frizzi, “Conflictos agrarios”, pp. 77-81. Sobre la falsificación de títulos véase, entre otros, BARrera y BARrera, "La falsificación de títulos”.

16 Véase, por ejemplo, FAlcón, “Litigios interminables” y Fenner, "Pérdida o permanencia”, p. 13. 
nación explicando que varias haciendas colindantes habían rebasado los linderos demarcados en los títulos primordiales y en el mapa del pueblo y, por lo tanto, habían llevado la demanda al Juzgado de Atlixco. Se quejaban de que llevaban más de tres años "gastado la cantidad de mil seiscientos noventa y cinco pesos cuatro reales. Dicha cantidad ha sido invertida en este negocio y que nos han demorado en dar la sentencia". ${ }^{17}$ Asimismo, en el Estado de México, en 1859, los pobladores de San Felipe Coamango se quejaron de que llevaban casi 30 años gestionando sus derechos ante la presunta usurpación de sus tierras por la hacienda Doxichó. ${ }^{18}$

Durante la Reforma (1855-1861) algunos gobernadores propusieron alternativas para resolver de manera administrativa la profusión de litigios pendientes entre pueblos o entre pueblos y particulares. En Veracruz, por ejemplo, el gobernador Ignacio de la Llave promovió la desamortización como solución para reducir "la multitud de litigios que sostienen las comunidades indígenas, con perjuicio no sólo de los que los promueven sino también de los colindantes". ${ }^{19}$ Para terminar con las demandas pendientes entre los pueblos, los funcionarios de los ayuntamientos debían nombrar a jueces árbitros, arbitradores o amigables componedores. ${ }^{20}$ En Jalisco el gobernador, general Anastasio Parrodi, estableció el Séptimo Juzgado de Letras "para que conozca única y exclusivamente de todos los negocios contenciosos que se hallen pendientes, o que se inicien en lo sucesivo sobre tierras, en que tengan interés como actores

17 AGN, G-leg, c. 1255, exp. 5/8, f. 1 (3 de agosto de 1857).

${ }^{18}$ Falcón, El jefe político, p. 422.

19 AGN, JPCM, c. 1, exp. 5, f. 97 (abril de 1856).

${ }^{20}$ AGN, JPCM, c. 1, exp. 5, f. 97. 
o demandados los llamados indígenas" ${ }^{21}$ La meta era promover la conciliación. En caso de que el avenimiento de las partes no se lograra, los jueces de los tribunales especiales debían resolver la demanda en la mitad del tiempo ordinario. Los indígenas podían decidir si querían seguir los juicios pendientes (o entablar nuevos) ante los tribunales de primera instancia o ante este Séptimo Tribunal Especial. ${ }^{22} \mathrm{Y}$ en Michoacán, el gobernador Epitacio Huerta nombró un juez letrado para cada uno de los departamentos del estado, "que se encargará única y exclusivamente de resolver en primera instancia todos los negocios pendientes en que tuvieron parte las antiguas comunidades de indígenas, o que promovieron ellos o sus colindantes sobre tierras". ${ }^{23}$ Los juicios tenían que ser verbales, los procedimientos, sumarios y rápidos, y los jueces debían enviar al gobernador informes sobre los juicios cada 15 días.

El problema de cómo resolver sumariamente los cuantiosos conflictos por las tierras de los pueblos atrajo la atención de los funcionarios del Segundo Imperio (1864-1867). La ley para dirimir las diferencias sobre tierras y aguas entre pueblos, por ejemplo, dio a los prefectos la autoridad de resolver en primera instancia las demandas de los pueblos por "la propiedad o posesión de tierras o aguas a otro pueblo o propietario particular". ${ }^{24}$ Cuando se tratara de una disputa entre dos pueblos, los prefectos no debían darles

${ }^{21}$ Colección de acuerdos, órdenes y decretos, vol. III, p. 94 (22 de octubre de 1857).

${ }^{22}$ Colección de acuerdos, órdenes y decretos, vol. III, pp. 92-96.

${ }^{23}$ Ley Expedida por el Gobierno del Estado de Michoacán en 15 de setiembre [sic] de $1859 . . .$, p. 1.

${ }^{24}$ Ley del $1^{\circ}$ de noviembre de 1865, en Fabila, Cinco siglos, p. 126. 
licencia para litigar entre sí y, en vez de eso, “mandarán dar la posesión al que tenga mejor derecho"; cuando se tratara de una disputa entre un pueblo y un particular, los prefectos “otorgarán licencia a los pueblos para demandar a particulares, si del examen de los documentos resultare que hay justicia para ello". ${ }^{25}$

Algunos representantes no tardaron en aprovechar esta ley para esquivar a los juzgados. En Morelos, por ejemplo, Marino nos dice que los representantes de Tepoztlán celebraron tener un gobierno "que defendía la cultura jurídica de antiguo régimen, donde el gobernante podía arbitrar entre las corporaciones, ejerciendo la justicia fuera de los tribunales". ${ }^{26}$ Sin embargo, esta reorganización de poderes administrativos y judiciales parece haber tenido sus complicaciones porque, menos de un año más tarde, Maximiliano derogó la ley de 1865. Advirtiendo que los prefectos estaban aliados con los terratenientes, una nueva ley agraria de septiembre de 1866 les ordenó que enviaran todas las demandas de los pueblos a los jueces de distrito, en donde los juicios serían sumarios: "Los juicios sobre posesión o propiedad de tierras y aguas que promueva un pueblo contra otro o contra algún propietario particular, o éste contra aquél - explica la ley-, se sustanciarán y decidirán por los jueces y tribunales ordinarios a la mayor brevedad posible". ${ }^{27}$

Cuando en la República Restaurada (1867-1876) la Constitución federal de 1857 recobró vigencia, no quedaba duda

25 Ley del $1^{\text {o }}$ de noviembre de 1865, en Fabila, Cinco siglos, p. 127.

26 Marino, “La modernidad a juicio”, p. 421.

27 Ley Agraria del Imperio que Concede Fundo Legal y Ejido a los Pueblos que Carecen de él (16 de septiembre de 1866), en Fabila, Cinco siglos, pp. 131-132. 
de que el Poder Judicial estaba a cargo de los juicios de reivindicación y del apeo y deslinde de las tierras de los pueblos. ${ }^{28}$ Sin embargo, los gobiernos de los estados con terrenos comunales continuaron buscando la manera de resolver las numerosas contiendas de manera administrativa. El Congreso del Estado de Puebla, por ejemplo, decretó en 1869 una ley que disponía que "los litigios pendientes entre pueblos del estado, o los que en lo sucesivo se promuevan, serán terminados por medio de árbitros amigables componedores, uno por cada parte, que nombrarán los representantes de los ayuntamientos a pueblos interesados". ${ }^{29}$ En cuanto a los litigios con los particulares, "el Ejecutivo hará todo lo posible para que éste se preste a que el litigio se decida" por árbitros. ${ }^{30}$

En el material de archivo queda claro que los representantes de los pueblos siempre intentaban utilizar las leyes a su favor. Cuando la intervención de los funcionarios del gobierno estatal no les convenía, demandaban la intervención de los jueces. Por ejemplo, cuando en agosto de 1871 el gobernador de Oaxaca, Félix Díaz, ordenó al jefe político que estableciera una línea divisoria entre los terrenos de dos pueblos del distrito de Coixtlahuaca, Tequixtepec y Tepelmeme, los vecinos de Tequixtepec argumentaron lo siguiente:

28 James, Mexico's Supreme Court, p. 59.

${ }^{29}$ Gobierno del Estado Libre y Soberano de Puebla, Decreto Núm. 122 del $2^{\circ}$ Congreso Constitucional, en Mallon, Peasant and Nation, p. 121. Cita en Marino, "La medida de su existencia", p. 297.

30 Marino, "La medida de su existencia”, p. 298. 
Considerando que, según las leyes, establecer líneas divisorias en terrenos de propiedad particular, aun cuando sea con el carácter de provisional, no es facultad del Poder Ejecutivo, sino del Judicial, a quien además corresponde por medio del juicio respectivo, conocer del valor de los títulos en que la misma propiedad se funda. ${ }^{31}$

Igualmente, en Oaxaca, el síndico municipal de Tejupam demandó a la autoridad política del distrito de Teposcolula por haber interferido en un litigio sobre posesión de terrenos en contra del pueblo de Tamazulapan, argumentando lo siguiente:

[...] el artículo 50 de la Constitución federal, expresamente claro en esta materia, dice así: "El supremo poder de la federación se divide para su ejercicio en Legislativo, Ejecutivo y Judicial. Nunca podrán reunirse dos o más de estos poderes en una persona o corporación”. Ahora más, el artículo 13 de la misma ley fundamental dice: "En la República Mexicana nadie puede ser juzgado por leyes privativas, ni por tribunales especiales". ${ }^{32}$

En la ejecutoria de la Suprema Corte de Justicia los magistrados fallaron a favor del síndico, explicando que "los juicios sobre posesión, deslinde y otros relativos a terrenos no es de la facultad del Poder Ejecutivo sino del Judicial, a quien además corresponde por medio del juicio respectivo

31 Cabrera Acevedo, La Suprema Corte de Justicia en la República Restaurada, 1867-1876, pp. 53-54.

32 Semanario Judicial, época 1, t. 5, p. 605 (6 mar. 1874). 
conocer del valor de los títulos en que la propiedad de las comunidades o de los particulares se funde". ${ }^{33}$

Sin embargo, cuando a los apoderados de los pueblos se les hacía imposible resolver los conflictos en los tribunales, enviaban peticiones o comisiones a las secretarías de gobierno o al Poder Ejecutivo de los estados. En el Distrito Federal, por ejemplo, líderes de 11 pueblos firmaron una solicitud a la Secretaría de Gobernación para que se les permitiera recobrar unos terrenos de que se decían despojados "con sólo la intervención de las autoridades locales gubernativas". ${ }^{34}$ Explicaron que,

[...] aunque es cierto que hay tribunales establecidos exclusivamente para juzgar esta clase de contiendas, es de advertir que los pueblos, en diferentes tiempos y ante esos tribunales, han entablado sus demandas y empeñado todos sus elementos para hacer valer sus derechos conculcados, pero estos han sido estériles, porque jamás hemos tenido resultado favorable, como se verá en los voluminosos expedientes que se hayan archivados en las oficinas de aquéllos. ${ }^{35}$

Durante el porfiriato, los jueces y ministros precisaron la facultad y competencia del Poder Judicial en cuanto a los juicios de reivindicación y a los de apeo y deslinde de las tierras de los pueblos, controlando quiénes tenían derecho a litigar y prohibiendo a los funcionarios del Ejecutivo inmiscuirse en asuntos contenciosos en los que las partes tenían derecho a ser oídas.

33 Semanario Judicial, época 1, t. 5, p. 608.

34 AGN, Gs/s, secc. 2a877(8)4, c. 72, exp. 143, f. 2 (diciembre de 1877).

35 AGN, Gs/s, secc. 2a877(8)4, c. 72, exp. 143, f. 11. 
Una manera en la que la Suprema Corte defendió su autoridad fue otorgando o negando la personalidad jurídica a las corporaciones en asuntos de tierras, ya que con la Ley Lerdo de 1856 y la Constitución de 1857 los pueblos habían perdido la capacidad jurídica para ser sujetos de una relación procesal. Por una parte, en la década de 1880, la Suprema Corte consideró anticonstitucionales varias leyes estatales que concedían a los jefes políticos la autoridad de dar o negar licencia para litigar a los pueblos. ${ }^{36}$ Por ejemplo, el Estado de México había promulgado una ley en 1868 que permitía a los jefes políticos decidir si las disputas por las tierras merecían un permiso para litigar, pero en 1878-1880 los jueces federales fallaron en contra de este derecho. ${ }^{37}$

La Suprema Corte creó un panorama inseguro en cuanto al otorgamiento o la negación de la personalidad jurídica a las corporaciones en asuntos de tierras. A pesar de que el amparo siempre fue un derecho individual, durante la República Restaurada la Suprema Corte había reconocido la personalidad de las comunidades indígenas y les concedió lo que Lucio Cabrera Acevedo llama "el amparo comunal". ${ }^{38}$ No obstante, durante el porfiriato el derecho al amparo comunal muchas veces fue negado, en especial durante la presidencia del ministro Ignacio Vallarta en $1879-1882 .{ }^{39}$

${ }^{36}$ Dos ejemplos son la Ley Estatal Mexiquense de abril de 1868 (Marino, "La fuerza de la ley", p. 223) y el Decreto del Estado de Hidalgo del 21 de abril de 1869 (KNowlton, “Tribunales federales”, pp. 84-85).

37 Falcón, El jefe político, p. 418 y Marino, "La medida de su existencia”, pp. 293-294.

38 Cabrera Acevedo, La Suprema Corte de Justicia, p. 53; Knowlton, “Tribunales federales", p. 72.

39 Knowlton, "Tribunales federales", pp. 71-98; Cabrera Acevedo, La Suprema Corte de Justicia en el primer periodo, pp. 569-571; GonZÁLEZ 
Por lo tanto, entre 1882 y 1911, la capacidad jurídica de los apoderados de los pueblos para ser sujetos de una relación procesal fue incierta. El trabajo de Marino muestra que Silvestre Moreno Cora, ministro presidente en 1900, fue pragmático en este tema, al resolver favorablemente recursos de amparo interpuestos por funcionarios del ayuntamiento. ${ }^{40}$ Por su parte, Justus Fenner encuentra que, de 1876 a 1910 en Chiapas, el Juzgado de Distrito a cargo de los juicios sobre denuncios de tierras baldías nunca desconoció la personalidad jurídica de los representantes o apoderados de los ayuntamientos indígenas. ${ }^{41} \mathrm{Y}$ aun así no quedaba del todo claro en qué casos los apoderados de los pueblos podían solicitar protección y amparo del Poder Judicial.

En algunos casos, la Suprema Corte les concedió amparo a los vecinos que se presentaban como una colectividad de individuos. ${ }^{42}$ En el Estado de México, por ejemplo, la Suprema Corte amparó al apoderado y a los vecinos de Amecameca contra la sentencia pronunciada por el juez de distrito que les negaba el derecho de litigar. La disputa se originó cuando, en 1889, un individuo denunció ante Fomento las excedencias de varias haciendas colindantes con Amecameca, las cuales incluían, según los vecinos, derechos de propiedad en los terrenos de bosques y pastos. El juez

\footnotetext{
Navarro, "Vallarta, indios y extranjeros", pp. 1975-1976; Marino, "Buscando su lugar", p. 245. Para las sociedades agrícolas, véase Neri Guarneros, "Sociedades agrícolas en resistencia”, pp. 21-44.

40 Marino, "Buscando su lugar en el mundo", pp. 295, 296; "La fuerza de la ley”, p. 228, y "La medida de su existencia”, pp. 301-303.

${ }^{41}$ Fenner, "Pérdida o permanencia", p. 18.

${ }^{42}$ Marino, "La medida de su existencia", p. 308.
} 
de distrito desechó la petición de amparo, pero en 1901, la Suprema Corte revocó la sentencia del juez explicando que,

[...] desde el momento en que los demandantes no se presentaron con el carácter de comuneros sino por su propio derecho individual, por más que [en] los títulos por ellos presentados para justificar su propiedad apareciera que los terrenos que demandaban fueran comunales, no dejaban de tener personalidad, supuesto que no se presentaron como representantes de la comunidad sino por su propio derecho. ${ }^{43}$

Por otra parte, la influencia de Vallarta fue profunda, y no fue sino hasta el 9 de diciembre de 1911 - es decir, después de la caída de Porfirio Díaz-, cuando la Suprema Corte amparó a la comunidad de la Vega de Metztitlán, Hidalgo, contra actos de su legislatura y su gobernador y, según Cabrera Acevedo, "renació el reconocimiento a la personalidad jurídica de las comunidades en cuatro ministros del Alto Tribunal". ${ }^{44}$

Además de defender la jurisdicción del Poder Judicial federal al otorgar o negar la personalidad jurídica a las corporaciones, los jueces y los ministros lograron preservar su facultad y competencia prohibiendo a los funcionarios del Ejecutivo resolver asuntos contenciosos resultantes del apeo y deslinde de los terrenos de los pueblos. En los trabajos periciales de deslinde se fijaban los límites y se definía la extensión de los terrenos de los pueblos y, de esta manera, se establecían derechos de propiedad. Por ejemplo, en el amparo de la señora Servín de Capetillo de 1878,

43 Semanario Judicial, época 4, t. 9, p. 245 (20 nov. 1901).

${ }^{44}$ Cabrera, La Suprema Corte de Justicia, pp. 22-23. 
la Suprema Corte explicó que la acción de apeo y deslinde era "un medio por el que se llega a la propiedad rústica y por eso la esencia del derecho dice que hace las veces de la vindicación de la cosa". ${ }^{45}$ Por lo tanto, muchas veces los representantes de los pueblos pedían la desamortización de los terrenos comunales como una estrategia de reivindicación, ya que el primer paso para ello era la definición de los linderos de las tierras de los pueblos, y estos confines podían ser más extensos de lo que poseían en esos momentos. ${ }^{46}$

Cuando el deslinde afectaba a un pueblo colindante o a un particular, éstos tenían el derecho a ser oídos y vencidos en un juicio sustanciado ante una autoridad competente. En estos casos, explica Robert Knowlton, "las repetidas solicitudes de ayuda al gobernador durante el decenio de 1880 obtuvieron invariablemente el mismo tipo de respuesta [...]: se trataba de un asunto judicial que debía ventilarse en los tribunales, no de un asunto del Ejecutivo". ${ }^{47}$ En el Distrito Federal, por ejemplo, el apoderado de San Andrés Mixquic y 30 firmantes se quejaron "del despojo cometido por el síndico de su ayuntamiento que tomándose atribuciones judiciales, practicó un deslinde y repartimiento de terrenos

45 Cita en Marino, “La medida de su existencia”, p. 295.

46 Véanse, por ejemplo, las solicitudes de 1882 para el apeo y deslinde de los terrenos comunales de los vecinos de San Pedro Totoltepec y del barrio de La Concepción (Estado de México) en Neri Guarneros, "Sociedades agrícolas", p. 31; la solicitud de 1890 de Dzitbalché (Yucatán) en AGA, Dzitbalché, Calkini, Yucatán, 23/140: 0: 19, ff. 22-23; la de 1895 de Tlancualpican (Puebla) en Ávila Espinosa, Los orígenes del zapatismo, p. 260 y la de 1899 de Tekit (Yucatán) en Ortiz Yam, "Formación de ejidos", pp. 26-27.

47 Knowlton, "La división de las tierras", p. 8. 
que poseían legalmente vecinos de Axolocalco". ${ }^{48}$ El juez de distrito otorgó el amparo argumentando que, "sea cual fuere el motivo de la intervención del ayuntamiento en las expresadas disensiones, siempre será cierto que se abrogó facultades que están reservadas a la esfera judicial" ${ }^{49}$ En este caso, los ministros de la Suprema Corte confirmaron la sentencia por unanimidad de votos. En Tabasco, el juez de distrito y la Suprema Corte concedieron amparo a los residentes de Huimanguillo en contra del gobernador porque los había privado de sus posesiones durante el deslinde y fraccionamiento de los ejidos. La Suprema Corte resolvió que "los quejosos estaban en posesión de los terrenos y casas de que se les ha privado sin haber sido oídos ni vencidos en el juicio civil sustanciado ante la autoridad competente; y que este despojo se ha ejecutado por una orden administrativa [...] por lo que el procedimiento carece de motivo y causa legal que lo funde". ${ }^{50}$ En Oaxaca, el gobierno estatal y el Poder Judicial federal disputaron esta autoridad. Mientras que la ley de 14 de diciembre de 1891 le dio facultades extraordinarias al gobierno del estado (incluyendo a las autoridades municipales y a los prefectos) para definir los límites de los pueblos y así "servir al cumplimiento de las disposiciones federales que mandan dividir los terrenos de las comunidades para ser adjudicados en lotes a sus vecinos", la Suprema Corte consideró esta ley como inconstitucional. ${ }^{51}$ Finalmente en Durango, cuando el jefe político

\footnotetext{
48 Semanario judicial, época 2, t. 12, p. 668 (17 jun. 1887).

49 Semanario judicial, época 2, t. 12, p. 670.

50 Cita en Knowlton, “Tribunales federales”, p. 93 (27 de junio de 1893).

51 Purnell, “Citizens and Sons”, pp. 221-222, 226-227, cita en ACSCJN, exp. 2398.
} 
de Cuencamé definió los límites de los pueblos de Santiago y San Pedro Ocuila y la hacienda El Sombreretillo, la Suprema Corte de Justicia amparó y protegió a los promoventes contra estos actos. ${ }^{52}$

Mientras que los tribunales preservaban sus facultades y competencias sobre los juicios de apeo y deslinde, para los vecinos de los pueblos el Poder Judicial seguía siendo costoso y dilatado, por lo que trataban de resolver sus querellas administrativamente. En Michoacán, por ejemplo, más de 100 indígenas y vecinos de Tanaco pidieron al gobernador que resolviera los conflictos por límites con los pueblos vecinos de Urén, Cheranatzicurín, Ahuiran y Urapicho. Habían entablado un juicio, pero desistieron tanto "por lo interminable de los trámites judiciales como por falta de fondos". ${ }^{53}$ Preguntaron:

Si en nuestra República ha habido un hombre que ha podido establecer la paz entre sus habitantes, desde la cual estamos disfrutando desde como hace veinte años [...] ¿ ¿por qué el Supremo Jefe del Estado no se resuelve a dictar sus sabias y prudentes determinaciones gubernativas para que se fijen los linderos de cada pueblo y, una vez conocida, cese la incertidumbre que nos rodea [y evite] un pleito a mano armada, por mantener la integridad de nuestros terrenos hasta donde los títulos nos dicen "Hasta aquí es lo tuyo"?54

52 AGA, General Severino Ceniceros (Antes Santiago y San Pedro Ocuila), Cuencamé, Durango, exp. 24/703, leg. 3, fs. 70-74, 127-128 (24 de abril de 1900).

${ }^{53}$ Citado en ZÁrate, "Comunidad, reformas liberales", p. 38 (20 de agosto de 1903).

${ }^{54}$ Citado en ZÁrate, “Comunidad, reformas liberales”, p. 38. 
Este forcejeo entre las peticiones populares para que el Ejecutivo interviniera en asuntos contenciosos y la defensa del Poder Judicial de su jurisdicción fue un largo e importante proceso histórico previo a la Revolución.

LA POLÍTICA AGRARIA MADERISTA: UNA OPORTUNIDAD PARA SOLICITAR LA RESOLUCIÓN DE LOS CONFLICTOS POR LAS TIERRAS POR LA VÍA ADMINISTRATIVA

Cuando en el artículo 3 del Plan de San Luis Potosí Madero ofreció revisar las disposiciones y fallos con los cuales a los pueblos se les había despojado de sus terrenos y prometió restituirlos a sus antiguos poseedores, cientos de representantes enviaron solicitudes o se presentaron ante las oficinas del Ejecutivo federal pidiendo que les hiciera justicia fuera de los tribunales. ${ }^{55}$ En Sinaloa, por ejemplo, los naturales del pueblo de Ocoroni le pidieron a Fomento que resolviera un litigio pendiente desde 1880 en contra de varios denuncios a sus propiedades. ${ }^{56}$ En el Estado de México, los líderes de Xilotepec explicaron que desde hacía varios años los hacendados habían ampliado la parte principal de su hacienda invadiendo terrenos del pueblo. Agregaron que "la defensa de nuestros intereses ha sido o mal hecha por las influencias de rico o ahondadas por nuestra falta de recursos para pagar a nuestros abogados" ${ }^{57}$ También en el Estado de

55 Artículo 3 del Plan de San Luis Potosí (5 de octubre de 1910), en Fabila, Cinco siglos, pp. 177-180. Las solicitudes se encuentran en el AGN, $M$ y en AHUNAM, $A G M, L B$.

${ }^{56}$ AGN, $M$, c. 64, exp. 2766, s. f. (16 de noviembre de 1911).

${ }^{57}$ AGN, $M$, c.64, exp. 2879, s. f. (9 de enero de 1912). 
México, una comisión procedente del pueblo de Jocotitlán pedía:

[...] que se apresure el deslinde de los terrenos de ese pueblo con la hacienda de Teacaque [...] que desde hace como diez años que sucesivamente ha ido invadiendo los terrenos de los vecinos de Jocotitlán. Hace siete años que el litigio está entablado [...] ventilándose este asunto en el Juzgado Tercero de lo Civil, pero hasta la fecha nada han conseguido. ${ }^{58}$

Si los representantes de pueblos interpretaron el artículo 3 del Plan de San Luis como una promesa de que el Ejecutivo se haría cargo de las reivindicaciones de las tierras de los pueblos, las dos circulares expedidas por el secretario de Fomento, Rafael Hernández, en enero y febrero de 1912, crearían aún más expectativas. Con estas circulares Hernández trató de acelerar la política desamortizadora para solucionar los conflictos por las tierras, otorgándole a los ayuntamientos la personalidad jurídica para promover el deslinde, fraccionamiento y reparto "de los ejidos de los pueblos". ${ }^{59}$ Hernández explicó que era "políticamente y económicamente conveniente atender a las demandas y quejas [...] y procurar remediarlas en lo que sea posible dentro de su esfera de acción administrativa" ${ }^{60}$ Para esto, pidió a los gobernadores que contrataran agrimensores para el deslinde y amojonamiento del ejido. Lo urgente era delimitar

${ }^{58}$ Cita en El País (13 abr. 1912), p. 3. Véase también AGN, SJ, c. 756, exp. 1707, ff. 1-4.

${ }_{59}$ Circular del 8 de enero de 1912, en Colección de leyes sobre tierras, p. 172.

${ }_{60}$ Circular del 17 de febrero de 1912, en Colección de leyes sobre tierras, p. 174. Cursivas de la autora. 
las tierras de los pueblos, dejando para más tarde su reparto y privatización. Si durante la delimitación de las tierras "los dueños de predios colindantes que hayan invadido los terrenos de ejidos consideran que tienen mejor derecho, habrá lugar a examinar sus pretensiones en vista de los documentos justificativos que presenten, y resolver administrativamente por esta Secretaría las diferencias que se susciten" ${ }^{61}$

Madero no tenía planeado infringir la esfera judicial. La Secretaría de Fomento, en su circular número 2, agregó que dejaba a salvo "los derechos de los que no queden conformes con la resolución [administrativa], para que los hagan valer ante las autoridades judiciales que sean competentes para conocer el asunto". ${ }^{62}$ Más aún, en un informe de su gobierno de abril de 1912 Madero explicó que la intención del Plan de San Luis había sido que, "mediante procedimientos jurídicos de revisión, se determinaría en qué casos los pequeños propietarios, especialmente los indígenas, habían sido indebidamente despojados de sus terrenos, para restituir éstos en especie u obligar a pagar una indemnización al responsable del despojo". ${ }^{63}$ No obstante, en el diluvio de solicitudes a Fomento para deslindar y amojonar "sus ejidos", posterior a la publicación de las circulares, es notable

${ }^{61}$ Circular del 17 de febrero de 1912, en Colección de leyes sobre tierras, pp. 174-175.

${ }_{62}$ Circular del 17 de febrero de 1912, en Colección de leyes sobre tierras, p. 175.

63 "Primer Informe de Gobierno del Presidente Constitucional de los Estados Unidos Mexicanos”, Francisco I. Madero (1º de abril de 1912), en Secretaría de la Reforma Agraria y Secretaría de la Presidencia, México a través de los informes, pp. 44-45. Cursivas de la autora. 
la expectativa de los pobladores de que el Ejecutivo resolvería los conflictos de manera administrativa. ${ }^{64}$

En los expedientes hallados en los archivos hay principalmente dos tipos de solicitudes. Primero, un número de apoderados aprovecharon las circulares de Fomento para solicitar la verificación de los procedimientos de desamortización pasados. En Aguascalientes, por ejemplo, vecinos de San José de Gracia pidieron que se revisara el reparto hecho hacía 20 años. Recordándole a Madero que habían sido simpatizantes de la "gloriosa revolución", solicitaron que "dentro de la esfera administrativa nos ayude en el presente caso con su valioso contingente para el deslinde y medición de nuestros ejidos". ${ }^{65}$ En Guerrero, 70 vecinos de Malinalco acusaron al jefe político y al juez de primera instancia de haberse apoderado de los terrenos del pueblo durante la desamortización que se había practicado en 1878 y solicitaron a Madero que se revisaran "nuevamente los linderos que marca el título y mapa de nuestro terreno". ${ }^{66}$ En San Luis Potosí, alrededor de 110 vecinos de San Martín Chalchicuautla dijeron haberse enterado del decreto de Fomento aprobado por Madero y, por lo tanto, pedían el reparto "de los terrenos de los ejidos o común repartimiento de este municipio", ya que el cacique del pueblo los dejó "a todos los pobres muy arruinados por haber hecho el reparto a su antojo y no arreglado a la ley y haber vendido el terreno

${ }^{64}$ Un informe oficial reportó 187 solicitudes de pueblos, incluyendo 60 de Puebla, 50 del Estado de México y 26 de Michoacán. Véase Secretaría de Fomento, Memoria de la Secretaría de Fomento... 1913, pp. lxxii-lxxv.

${ }^{65}$ AGN, $M$, c. 14, exp. 326, f. 010503-010504 (5 de abril de 1912).

${ }^{66}$ AGN, $M$, c. 64, exp. 2894, s. f. (30 de junio de 1912). 
nada más a un grupo de indígenas que patrocinaba” ${ }^{67} \mathrm{El}$ apoderado agregó que los indígenas y vecinos que representaba pertenecían al Partido Maderista y, por lo tanto, pidió que les mandaran armas para 500 hombres. ${ }^{68}$ Y en Veracruz, miembros de la junta establecida para el reparto de terrenos de San Andrés Tuxtla explicaron que, durante la desamortización de los terrenos comunales en 1886, "la voluntad de los señores que formaron la junta divisionista se impuso de manera más desautorizada y descarada, en perjuicio nuestro". ${ }^{69}$ Pidieron que se hiciera la medición y el deslinde de los terrenos que quedaron sin dividirse y que la junta divisionista se apropió ilegalmente. ${ }^{70}$

El segundo tipo de solicitud en respuesta a las circulares de Fomento era la restauración de las tierras usurpadas. En Michoacán, por ejemplo, más de 100 vecinos de Panindícuaro firmaron una petición dirigida al secretario de Fomento pidiendo que se procediera "al señalamiento del perímetro conforme a los títulos que amparan la propiedad” del pueblo. ${ }^{71}$ También en Michoacán, el síndico procurador del pueblo de Huarachita dijo haberse enterado de que el presidente estaba dispuesto a la reivindicación de fundo legal y ejidos. Fueron a la Sección Agraria de la Secretaría de Fomento a presentar sus títulos, “pidiendo que el señor

\footnotetext{
67 AGN, $M$, c. 64, exp. 2791, s. f. (8 de septiembre de 1912).

68 AGN, $M$, c. 64, exp. 2791, s. f.

69 AGN, GPR, c. 1, exp. 19, f. 1 (15 de enero de 1913).

70 En respuesta, Fomento envió la solicitud al gobernador y tres meses más tarde el prefecto solicitó que enviaran un agrimensor. AGN, GPR, c. 1, exp. 19, ff. 1-11.

71 Diario del Hogar (3 feb. 1912), p. 3.
} 
hacendado de Huaracha exhiba los suyos".$^{72}$ En el Estado de México, pobladores de la ranchería San Antonio Pachuquilla pidieron, "ahora que el nuevo régimen concede tantas garantías a todos los habitantes en general”, que Fomento deslindara sus terrenos "con vista de los títulos que amparan nuestra propiedad, pues los dueños de la hacienda de Jaltepec, nos han venido despojando de grandes extensiones de la tierra que nos pertenece según es de verse por el testimonio de la merced de [...] 1584". ${ }^{73}$ En este mismo estado, una comisión de Jocotitlán le pidió a Madero "que se apresure" el deslinde de los límites del pueblo con los de la hacienda Teacaque, propiedad de María del Valle Mier y Terán, quien presuntamente había invadido sus terrenos durante la última década y contra quien habían entablado un juicio que en siete años no se había resuelto. ${ }^{74} \mathrm{Y}$ en Puebla, 11 pueblos del distrito de Tepeaca pidieron el deslinde y fraccionamiento de los terrenos "que forman los ejidos que les fueron concedidos en la época colonial", mientras que los vecinos de San Nicolás Tetitzintla pidieron a la Secretará de Fomento "el despacho de la justa y legal reclamación de los ejidos de este pueblo". ${ }^{75}$

72 El País (21 jul. 1912), p. 6.

73 AGN, $M$, c. 64, exp. 2911, s. f. (12 de septiembre de 1912).

${ }^{74}$ El País (13 abr. 1912), p. 3.

${ }^{75}$ El Imparcial (1º feb. 1913), p. 7 y AGN, GPR, c. 30, exp. 68, f. 1 (25 de febrero de 1913). Véase también la solicitud de 125 peticionarios de Villa Alta (Veracruz) en AGN, $M$, c. 52, exp. 1500-2, ff. 39921-39922 (12 de noviembre de 1912); la solicitud de 22 pobladores de Guadalajara en AGN, $M$, c. 76, exp. 21, f. 194 (12 de diciembre de 1912) y la solicitud de San Lucas Evangelista en AGN, $M$, c. 76, exp. 21, f. 230 (27 de diciembre de 1912). 
Varios gobernadores también aprovecharon las circulares de Fomento para tratar de resolver los conflictos por las tierras en sus estados. En San Luis Potosí, por ejemplo, el gobernador, doctor Rafael Cepeda, respondió a la solicitud de los vecinos de Villa de Reyes que pedían "se mandara practicar deslinde y amojonamiento de los ejidos del pueblo [de los cuáles presuntamente habían] sido despojados hace más de cien años por los dueños de la Hacienda de Gogorrón”, e informó que ya había enviado a Fomento la exposición en contra de los dueños de la hacienda. ${ }^{76}$ Por su parte, en Veracruz, el gobernador Antonio Pérez Rivera tuvo una actitud más proactiva al tratar de "solucionar equitativamente las cuestiones que han surgido entre algunas congregaciones del Cantón de Chicontepec y los colindantes a propósito del deslinde y fraccionamiento que estas congregaciones solicitan". ${ }^{77}$ Para esto, ordenó que las congregaciones presentaran sus títulos primordiales para resolver los conflictos "con pleno conocimiento de causa". ${ }^{78}$

En un reporte sobre el trabajo de Fomento entre julio de 1911 y junio de 1912, Hernández explicó que las circulares habían sido un éxito porque la Secretaría había arreglado dificultades con "juntas de avenencia de las partes, tratando de evitarles la necesidad de ocurrir a los Tribunales" ${ }^{79} \mathrm{Y}$ aun así, muchos propietarios se rehusaron a reconocer los apeos y deslindes bajo la coordinación de Fomento. En el distrito de Chalchicomula (Puebla), después de la demarcación de

\footnotetext{
76 Diario Oficial del Estado de San Luis Potosí(17 sep. 1912), p. 6.

77 El Imparcial (1º feb. 1913), p. 7.

78 El Imparcial (1º feb. 1913), p. 7.

79 Secretaría de Fomento, Memoria de la Secretaría de Fomento... 1913, p. 1xxiii.
} 
los linderos entre varios pueblos y propietarios contiguos, el representante de Santa Margarita reportó que los hacendados habían "armado a sus peones para impedir que se lleve a cabo el deslinde decretado por la Secretaría de Fomento", mientras que los hacendados se quejaban de que el representante de uno de los pueblos había mostrado "un documento burdamente falsificado, hecho sin duda por alguno de los tantos infames especuladores que explotan a los pueblos y los inquietan". ${ }^{80}$ Mientras tanto, en Puebla, cuando los vecinos de Santa Margarita Mazapiltepec solicitaron a Fomento el deslinde de sus terrenos, los propietarios colindantes se rehusaron a presentar los títulos que justificaban sus propiedades. ${ }^{81}$

El problema era que ni los agrimensores contratados por los pueblos, ni los funcionarios de Fomento, tenían la autoridad para medir los linderos de los pueblos cuando éstos invadían terrenos particulares (Fomento sólo tenía autoridad sobre terrenos nacionales y baldíos). Por lo tanto, los propietarios colindantes no tenían la obligación de mostrar sus títulos o de participar en las gestiones de mediación por parte del Ejecutivo. Según la Constitución de 1857, los terratenientes tenían el derecho de ser oídos y vencidos en juicio, y los tribunales federales defendieron activamente estos derechos.

Una y otra vez los jueces fallaron en contra del deslinde de los ejidos de los pueblos autorizado por Fomento. En este sentido, un caso del territorio de Tepic es ejemplar. En San Blas, en marzo de 1912, el presidente municipal

${ }^{80}$ El País (22 ago. 1912), p. 4.

${ }^{81}$ El Imparcial (5 ene. 1913), p. 4. 
recibió un telegrama de Fomento autorizándolo a proceder con el deslinde de los ejidos de acuerdo con las circulares 1 y 2. El síndico municipal procedió a hacer una lista de todos los residentes cabezas de familia y el presidente municipal reunió a los vecinos para decidir a cuál agrimensor contratar y hacer una colecta para cubrir sus honorarios. Los oficiales municipales notificaron al juez de distrito de Tepic, al representante de la Secretaría de Hacienda, al jefe político y a los propietarios colindantes para que presenciaran el deslinde. Tres días después de completar el deslinde, Leonor Mercado viuda de Romano y Leopoldo solicitó amparo al Juzgado de Distrito de Tepic en contra del ayuntamiento de San Blas por haber violado sus derechos bajo el artículo 16 constitucional ya que, según su abogado, deslindaron parte de su propiedad sin la formalidad judicial requerida. En contestación, el juez de distrito preguntó retóricamente:

[...] ¡ el deslinde y amojonamiento que comenzó a practicarse es ilegal y por lo mismo causa molestias injustificadas a los recurrentes que ameritan violación a las garantías que otorga el artículo dieciséis constitucional y dichos actos emanan de autoridad para que prospere el amparo y protección de la Justicia Federal ${ }^{82}$

Su respuesta fue que "los hechos encaminados a la rectificación y señalamiento de linderos practicados sin mediación ni orden de autoridad judicial competente es a todas luces ilegal". ${ }^{83}$ Para sustanciar el fallo, citó las tres circulares de 28 de octubre de 1889, la Ley de Tierras de 1894 y

${ }^{82}$ ACSCJN, exp. 998.

${ }^{83}$ ACSCJN, exp. 998. 
las circulares de Fomento de 1912, que señalaban que cuando los propietarios limítrofes se opusieran al deslinde, no se podía proceder legalmente por la vía administrativa. En abril de 1912, la Suprema Corte concedió el amparo a Leonor Mercado viuda de Romano y Leopoldo en contra del apeo y deslinde de sus posesiones que lindan con las de San Blas "sin orden o intervención de la autoridad judicial". ${ }^{84}$

Otro ejemplo interesante es el de Hampolol, Campeche. A finales del siglo XIx, el pueblo de Hampolol carecía de ejido y de fundo legal por estar enclavado en tierras de propiedad particular. Para recuperar sus presuntas tierras usurpadas, en 1899 los apoderados del pueblo entablaron un juicio de apeo y deslinde en el Juzgado de Distrito, el cual perdieron por no haber presentado sus títulos. Como resultado, varios propietarios colindantes concedieron un terreno para el fundo legal de Hampolol. No obstante, en 1906 los apoderados de Hampolol volvieron a entablar un juicio, en el cual, seis años más tarde, el juez aún no había dictado sentencia. Por lo tanto, en 1912 y con base en la circular núm. 1, el presidente municipal de Campeche y el comisario municipal de Hampolol solicitaron a Fomento - por medio del gobernador - el apeo y deslinde de los ejidos del pueblo como estrategia para recuperar lo que ellos consideraban sus terrenos usurpados.

Durante nueve días el ingeniero Francisco Campos Mena, encargado de la medición, amojonamiento y fraccionamiento de los ejidos, con la presencia del juez de paz del distrito y funcionarios municipales, midieron los linderos del ejido según la ley de Yucatán de $1844 .{ }^{85}$ Se ajustaron a esta

${ }^{84}$ ACSCJN, exp. 998.

${ }^{85}$ ACSCJN, exp. 4237. 
ordenanza antigua porque el artículo 67 de la Ley de Baldíos de 1894, resucitada por la circular número 1, ordenaba que para el señalamiento de los límites de los terrenos baldíos dotados a los pueblos que no los tuvieren, había que sujetarse "a los límites fijados en las concesiones otorgadas a los pueblos, ya por el Gobierno español en la época colonial, ya por los gobiernos de los estados en la época en que pudieron disponer de los baldíos". ${ }^{86}$

Al llegar a los $500 \mathrm{~m}$ en dirección norte de la iglesia se encontraron con el límite del fundo legal practicado en 1899 y con el terrateniente Eligio Guerrero, quien estaba presente en unión de su abogado exigiendo que se respetara su propiedad, que comenzaba en donde finalizaba el fundo legal que los propietarios colindantes le habían concedido a Hampolol en 1899. El ingeniero Campos Mena, no sin cierta prepotencia, descalificó los derechos de Guerrero de la siguiente manera:

Hojeando ligeramente los documentos y plano puestos a la vista por el señor Guerrero y de los cuales no quería desprenderse, y resultando que el documento con el que se pretende acreditar su propiedad no está de acuerdo con lo que manifiesta verbalmente [...] el plano que presenta como título ni concuerda con [las] fechas y sí está formada de manera privada sin que tenga anotación alguna oficial que acredite su legalidad ni acuse la conformidad de los colindantes [...] por lo que se supone haya lugar a examinar sus pretensiones por la Secretaría de Fomento de acuerdo con la circular núm. $2 .^{87}$

${ }^{86}$ Ley sobre Ocupación y Enajenación de Terrenos Baldíos de los Estados Unidos Mexicanos, en Secretaría de Fomento, Ley de Tierras de 26 de marzo de 1894 y sus reglamentos, pp. 22-23.

${ }^{87}$ ACSCJN, exp. 4237. 
No obstante, tuvo que conceder que se dejaban "a salvo sus derechos para ejercitarlos contra quien corresponda, en la vía legal" ${ }^{88}$

Después de ese encuentro tenso, el ingeniero Campos Mena y su comitiva prosiguieron el camino hasta llegar a los 2095 m, y en los días siguientes hicieron lo mismo en dirección de los otros tres puntos cardinales, "determinado el ejido por medio de un cuadrado cuya superficie es de 1753 ha 61 áreas o sea media legua cuadrada por viento o una legua por lado". ${ }^{89}$ Por su parte, Guerrero solicitó amparo al juez de distrito por dos violaciones a la ley. Primero, argumentó que el deslinde había sido ilegal porque había una demanda pendiente desde 1906 y, por lo tanto, estaba prohibida su discusión en cualquier otra parte (el principio sub judice). ${ }^{90}$ Y segundo, apuntó que el artículo 67 de la ley del 26 de marzo de 1894 y las dos circulares de 1912 "previenen que al iniciarse los trabajos deberán sujetarse a los límites fijados por la concesión otorgada al pueblo en su título correspondiente, lo cual no se ha hecho, pues no ha exhibido el título en que conste la concesión otorgada al pueblo de Hampolol". ${ }^{91}$ El juez de distrito negó el amparo por un tecnicismo, pero dos años más tarde la Suprema Corte se lo concedió. ${ }^{92}$

Al defender los derechos de propiedad privada inscritos en la Constitución de 1857, el Poder Judicial se convirtió en la traba de los intentos de la Secretaría de Fomento bajo

\footnotetext{
${ }^{88}$ ACSCJN, exp. 4237.

${ }^{89}$ ACSCJN, exp. 4237.

90 AGA, Hampolol, Campeche, exp. 23/117 (histórico), leg. 0, ff. 3, 6-10, 11-12, 13-18, 40-46, 64, 89 (septiembre a diciembre de 1912).

${ }^{91}$ ACSCJN, exp. 4237.

92 ACSCJN, exp. 4237.
} 
Madero por tratar de resolver dentro de su esfera administrativa los conflictos por las tierras de los pueblos. ${ }^{93}$ Como los funcionarios en la Ciudad de México eran conscientes del obstáculo que representaba el Poder Judicial para una pronta resolución de los conflictos por las tierras de los pueblos, hubo varias iniciativas alternativas en ese mismo año de 1912. En abril, por ejemplo, la Comisión Agraria Ejecutiva, compuesta por tres ingenieros y un exministro de Fomento, presentó una iniciativa para resolver las reclamaciones de los pueblos. Propusieron "instituir una comisión de letrados competentes y honorables, que estudien aquellos casos en que haya fundamentos para creer que cabe una restitución, indemnizando a los poseedores o en alguna otra forma que sea equitativa". ${ }^{94} \mathrm{El}$ problema era que, al igual que las circulares de Fomento, esta propuesta no resolvía el problema del derecho constitucional de los afectados a ser oídos y vencer en juicio.

En octubre de 1912, el diputado de la XXVI Legislatura, Juan Sarabia, propuso otra alternativa. El proyecto de reformas constitucionales formulado por la comisión agraria de la "extrema izquierda" del Parido Liberal explicaba que "si cada uno de los despojados se presenta con sus respectivas demandas ante los Tribunales de la Federación y de los estados, se entablarían juicios que no acabarían nunca". ${ }^{95}$

93 Véase también el amparo concedido al hacendado Diego Moreno en contra de la mensura del fundo legal y "los ejidos" de San Miguel Guarachita (Michoacán), en AGN, GPR, c. 55, exp. 42, f. 1 (8 de octubre de 1912), f. 16 (12 de noviembre de 1912) y f. 23 (23 de enero de 1913). ${ }^{94}$ Trabajos e iniciativas de la Comisión Agraria Ejecutiva, en SILva Herzog, La cuestión de la tierra, vol. in, p. 171.

${ }^{95}$ Sarabia, "Proyecto de ley sobre adiciones a la Constitución General 
Además, acusaba a los tribunales de los estados de estar subordinados al gobierno del estado - que calificó como peor intencionado que el gobierno federal-o, peor aún, sujetos al jefe político del distrito, como lo estaban los Juzgados de Primera Instancia. Por lo tanto, propuso reformar el artículo 13 constitucional y crear tribunales federales especiales para asuntos agrarios que,

[...] como jurados civiles, decidieran en breve plazo, previa práctica de diligencias relativas solamente a las pruebas de la posesión y al despojo, respecto a las restituciones a los pueblos, agrupaciones indígenas o pequeños propietarios, de las tierras, aguas o montes de que hubieren sido despojados por medio de violencia física o moral, o en virtud de contratos con apariencia legal. ${ }^{96}$

Si Sarabia hubiera tenido más influencia en el Congreso Constituyente de 1916-1917, quizá el artículo 27 habría creado un tribunal especial agrario - de la misma manera en que el artículo 123 creó Juntas Federales de Conciliación y Arbitraje para los conflictos laborales.

Finalmente, en diciembre de 1912, Luis Cabrera propuso otra manera de evadir al Poder Judicial. Criticó las circulares de Fomento preguntando:

¿Qué cosa más natural que, al triunfo de una revolución que prometió justicia, se pensase en llevar a cabo la reivindicación de los terrenos usurpados? [...] El sistema de las reivindicaciones, lógico pero ingenuo, fue aceptado, por

respecto de la materia agraria" (4 de octubre de 1914), en Silva Herzog, La cuestión de la tierra, vol. II, p. 229.

96 Sarabia, "Proyecto de ley", en Silva Herzog, La cuestión de la tierra, vol. II, p. 221. 
supuesto, por la Secretaría de Fomento desde luego; se invitó a todas las poblaciones que se encontraban en el caso de reivindicar sus ejidos, para que dijeran qué extensión más o menos habían tenido en épocas anteriores, y los identificaran, a ver si era posible hacer un intento de reivindicación. ${ }^{97}$

Pero no fue posible, según Cabrera, porque en $90 \%$ de los casos, los terrenos estaban amparados con títulos falsos pero válidos en apariencia. Por lo tanto, no se podía “fiar a la suerte de la reivindicación y a la incertidumbre de los procedimientos judiciales, aun abreviadísimos, como nos lo propone el ciudadano Sarabia". ${ }^{98}$ Agregó que "la cuestión agraria es de tan alta importancia, que considero debe estar por encima de la alta justicia, por encima de esa justicia de reivindicaciones y de averiguaciones de lo que haya en el fondo de los despojos cometidos contra los pueblos". 99

Este fue el escenario antes del asesinato de Madero: los representantes seguían exigiéndole al Ejecutivo la solución de sus conflictos por las tierras fuera de los tribunales, la autoridad judicial continuaba defendiendo su autoridad sobre los asuntos contenciosos, y las voces más radicales en la Ciudad de México proponían diferentes maneras de esquivar al Poder Judicial en la reivindicación de los terrenos usurpados de los pueblos. Sin embargo, un reajuste de las facultades y competencias entre ambos poderes probablemente no habría sido posible si no hubiera

97 Proyecto de ley agraria y discurso del diputado Luis Cabrera en Fabila, Cinco siglos, pp. 189-190. Para un análisis de las propuestas de Cabrera, véase Kourí, "Los pueblos y sus tierras".

98 Proyecto de ley agraria, en Fabila, Cinco siglos, p. 201.

99 Proyecto de ley agraria, en Fabila, Cinco siglos, p. 201. 
estallado una guerra civil entre las facciones revolucionarias después del golpe de Estado del general Victoriano Huerta.

\section{LA REFORMA AGRARIA CONSTITUCIONALISTA \\ Y EL PODER JUDICIAL}

En su Plan de Guadalupe de marzo de 1913, Venustiano Carranza, el autonombrado Primer Jefe del Ejército Constitucionalista y encargado del Poder Ejecutivo, desconoció el gobierno golpista de Huerta, incluyendo a los poderes Legislativo y Judicial. Esto dio a los carrancistas un margen de maniobra en el diseño de su ley agraria. Dejando a un lado las propuestas de sus aliados sobre el fraccionamiento de los latifundios, el 6 de enero de 1915, Carranza accedió a firmar un decreto redactado por Luis Cabrera, su entonces secretario de Hacienda. Titulado "Decreto que declara nulas todas las enajenaciones de tierras, aguas y montes pertenecientes a los pueblos otorgadas en contravención a lo dispuesto en la ley de 25 de junio de 1856", este fue un decreto de reivindicación de las tierras de los pueblos que - como lo había propuesto Cabrera dos años antes - estaba muy por encima de la alta justicia. ${ }^{100}$ En efecto, la restitución de Cabrera no se haría mediante de los tribunales sino por la esfera administrativa. Para esto, los carrancistas crearon órganos y autoridades agrarias dependientes del Poder Ejecutivo federal, no sólo con carácter administrativo sino con el de tribunales especializados, con comisiones locales agrarias y gobernadores fallando en primera instancia, y la Comisión Nacional Agraria y el presidente

100 Decreto de 6 de enero de 1915, en Fabila, Cinco siglos, pp. 228-236. 
en segunda instancia "como juez último". ${ }^{101}$ Como lo explicó Fernando González Roa en 1916, "la Comisión Nacional Agraria y sus dependientes, las comisiones locales de los estados, deberán constituir tribunales administrativos de jueces pesquisidores encargados [...] de resolver sobre el alcance y la legitimidad de los títulos". ${ }^{102}$ De esta manera, se descartaba "la solución ingenua de la restitución de las propiedades usurpadas por los procedimientos judiciales. Antes bien reestablece el principio de derecho colonial de la revisión administrativa, el cual principio fue mirado con desdén por el Gobierno del general Díaz". ${ }^{103}$ Lo que durante todo el periodo independiente de México hasta la fecha había sido facultad del Poder Judicial en la forma de juicios de reivindicación y de apeo y deslinde de las tierras de los pueblos se convertía en las restituciones carrancistas.

Los representantes de los pueblos no tardaron en aprovechar la ley agraria carrancista para tratar de solucionar de manera administrativa asuntos pendientes en los tribunales. En menos de un año, Fomento recibió casi 1000 solicitudes. ${ }^{104}$ En Guanajuato, por ejemplo, los indios nativos de San Bartolomé Aguascalientes pidieron al gobernador la restitución de un manantial usurpado hacía seis años por el dueño de la hacienda San Antonio Calichar. A pesar de haber obtenido un amparo ante el Juzgado de Distrito, los apoderados no lo lograron recuperar. Por lo tanto, en 1916 el representante de San Bartolomé solicitó su restitución, explicándoles a los funcionarios agrarios lo siguiente:

\footnotetext{
101 Chávez Padrón, El derecho procesal social agrario, p. 45.

102 González RoA, Parte general de un informe, p. 33.

103 González RoA, El aspecto agrario, p. 238.

104 UlloA, Historia de la revolución mexicana, pp. 368-370.
} 
[...] en el Archivo Nacional de Justicia obran los diversos juicios que tuvimos, defendiendo nuestros terrenos palmo a palmo, hasta quedar reducidos como estamos ahora los últimos atrincheramientos. Tengo fe en la revolución redentora de mi raza [y de] lograr esa rendición y no es precisa otra cosa que abrirnos las puertas de la justicia que hasta ahora se nos han cerrado injustamente. ${ }^{105}$

En Veracruz, el presidente municipal de Acula había demandado en 1912 al propietario colindante por haber invadido los terrenos del pueblo. Cuatro años más tarde, explicaron "que debido a los trastornos revolucionarios no pudo tener efecto la resolución de esta gestión” y, en vez de ello, acudieron a los funcionarios agrarios a pedir una restitución. ${ }^{106}$ En Tlaxcala, vecinos de varios pueblos solicitaron al gobernador, con apoyo a la ley de 6 de enero de 1915, que se les restituyera una extensión de terreno que habían adquirido en 1883, cuando 96 vecinos de varios pueblos se asociaron para adquirir en propiedad unos terrenos, pero que tres años más tarde el recaudador de contribuciones de Zacatelco les embargó por falta de pago de contribuciones. Los apoderados reclamaron este acto ante el juez de distrito, quien concedió un amparo, pero la Suprema Corte había revocado la sentencia del juez. ${ }^{107} \mathrm{Y}$ finalmente, en el Estado de México, los representantes del Mayorazgo de la

105 AGA, San Bartolomé Aguascalientes, Apaseo, Guanajuato, exp. 23/992, leg. 0, f. 2 (10 de enero de 1916).

106 AGA, Acula, Veracruz, exp. 23/5101, leg. 1, f. 10 (11 de abril de 1916).

107 En este caso, la Comisión Nacional Agraria negó la restitución porque los solicitantes eran vecinos de diferentes pueblos, y no eran los pueblos "jurídicamente y políticamente considerados los que solicitan la reivindicación de terrenos”. AGN, $S A F-C N A$, c. 1, exp. 1, fs. 52-55. 
Concepción de León solicitaron una restitución en noviembre de 1916, después de haber perdido una demanda cuatro años antes en el Juzgado de Distrito, más tarde confirmado por el Tribunal Superior de Justicia del Estado. ${ }^{108}$

Por su parte, las nuevas oficinas agrarias intentaron solucionar las cuestiones judiciales pendientes por medio de la ley de 6 de enero de 1915. Por ejemplo, cuando se estableció la Comisión Local Agraria del Estado de México, el presidente encontró un expediente de las gestiones que hicieron los vecinos de San Lucas Totomaloya en 1914 para recuperar los terrenos que presuntamente el dueño de La Estancia les había usurpado. En 1914, 65 vecinos de Totomaloya se habían quejado con el ayuntamiento de Aculco:

[...] que como consta de la escritura primordial que obra en nuestro poder, al pueblo de San Lucas de esta Municipalidad de donde somos originarios y vecinos, le fue quitada por los antiguos dueños de la hacienda de la Estancia nuestra colindante, una gran faja de terreno, la cual no hemos podido conseguir que nos sea devuelta no obstante las muchas gestiones que para ello hemos hecho, como debe constar en el archivo de la presidencia que hoy es a cargo de usted. Hoy que la revolución triunfante trae por lema proteger y hacer justicia a la clase desvalida a la que nosotros pertenecemos, venimos a pedir del Supremo Gobierno por el conducto de U. que previos los trámites de ley se sirva hacer que nos sea devuelto lo que tan injustamente nos ha sido arrebatado. ${ }^{109}$

108 AGA, Mayorazgo de la Concepción de León, Almoloya de Juárez, Estado de México, exp. 24/10926, leg. 3, fs. 5-8 (27 de noviembre de 1916). Los vecinos perdieron el amparo en 1912.

109 AGA, San Lucas Totomaloya, Aculco, Estado de México, exp. 24/2321, leg. 3, f. 2 (30 de septiembre de 1914). 
Los funcionarios del ayuntamiento respondieron que el asunto era "del resorte de la autoridad judicial a ella deben ocurrir en demanda de justicia". ${ }^{110}$ Sin embargo, les informó que, si deseaban "iniciar nuevas gestiones con el fin de lograr tal restitución”, lo podían hacer por medio del decreto de 6 de enero de 1915, expedido por el Primer Jefe del Ejército Constitucionalista. ${ }^{111}$

¿Eran más sumarias, rápidas e imparciales las restituciones carrancistas que los juicios que suplantaban? La ley de 6 de enero de 1915 no sólo sostenía la carga de la prueba de los juicios reivindicatorios decimonónicos, requiriendo que los demandantes mostraran títulos con linderos identificables y demostraran la fecha y circunstancia del despojo, sino que, además, ésta estaba limitada a tres posibles contextos. Primero, las autoridades estatales (presidentes municipales, jefes políticos, gobernadores, entre otros) tuvieron que haber vendido las tierras, aguas y montes de los pueblos en contravención de la Ley Lerdo, o sea, posterior a 25 de junio de 1856. Segundo, una autoridad federal tuvo que haber invadido ilegalmente las tierras de los pueblos y esto tuvo que haber sido a partir del $1^{\circ}$ de diciembre de 1876, o sea, desde el primer día del gobierno de Porfirio Díaz. Tercero, compañías, jueces u otras autoridades, de los estados o de la federación, tuvieron que haber invadido y ocupado ilegalmente las tierras de los pueblos al practicar diligencias de apeo o deslinde, y esto debió haber ocurrido

110 AGA, San Lucas Totomaloya, Aculco, Estado de México, exp. 24/2321, leg. 3 , f. 3 (7 de octubre de 1914).

111 AGA, San Lucas Totomaloya, Aculco, Estado de México, exp. 24/2321, leg. 3, f. 4 (10 de enero de 1917). 
también a partir del primer día del gobierno de Díaz. ${ }^{112}$ Conjuntamente, estos requisitos hacían que los procesos agrarios carrancistas fueran aún más onerosos que los juicios reivindicativos a cargo del Poder Judicial.

En su primer año de operaciones, la Comisión Nacional Agraria falló en 39 casos de restitución y únicamente promovió seis sentencias favorables. Esto lo previno Cabrera, abogado de profesión, al crear una forma de compensación e incluso una simplificación procesal para las restituciones negadas. En la ley de 6 de enero de 1915, Cabrera explicaba que era probable que

[...] en algunos casos no pueda realizarse la restitución de que se trata, ya porque las enajenaciones de los terrenos que pertenecían a los pueblos se hayan hecho con arreglo a la ley, ya porque los pueblos hayan extraviado los títulos o los que tengan sean deficientes, ya porque sea imposible identificar los terrenos o fijar la extensión precisa de ellos, ya, en fin, por cualquier otra causa [...] [por lo tanto] Los pueblos que necesitándolos, carezcan de ejidos o que no pudieren lograr su restitución [...] podrán obtener que se les dote del terreno suficiente para reconstituirlos conforme a las necesidades de su población. ${ }^{113}$

Este derecho se denominaría en la práctica "la dotación”. ${ }^{114}$

112 "Decreto de 6 de enero de 1915", en Fabila, Cinco siglos, p. 230.

113 “Decreto de 6 de enero de 1915”, en Fabila, Cinco siglos, pp. 229-231.

114 Para un análisis detallado de los primeros 200 expedientes de restitución y dotación, véase Helga Baitenmann, "Matters of Justice: Agrarian Reform and the Judiciary in Revolutionary Mexico”, inédito, cap. 4. 
EL PAPEL DE LA SUPREMA CORTE REVOLUCIONARIA

La ley de 6 de enero de 1915 fue un decreto provisional expedido por un autonombrado "Primer Jefe" en uso de facultades extraordinarias, durante una guerra civil en la cual el país no tenía un poder judicial federal. Y, sin embargo, los constituyentes de 1916-1917 la incorporaron al nuevo artículo 27, y los ministros de la nueva Suprema Corte, electos por el Congreso el $1^{\circ}$ de mayo de 1917 , avalaron incondicionalmente sus postulados. ${ }^{115}$ En efecto, desde su reinstauración, la Suprema Corte jugó un papel importante en la definición de facultades y competencias entre los poderes Ejecutivo y Judicial, porque los propietarios afectados por las restituciones y dotaciones de inmediato promovieron amparos. De 1917 a 1924, los ministros pronunciaron más de 300 fallos con relación a temas agrarios. En ellos, legitimaron la expansión del poder del Ejecutivo y justificaron la disminución de la autoridad que constitucionalmente le pertenecía al Poder Judicial. ${ }^{116}$

La primera Suprema Corte revolucionaria (1917-1919) desde luego ratificó los poderes extraordinarios del Ejecutivo. En una de las primeras ejecutorias sobre la cuestión agraria, Elena Sesma viuda de Ruiz promovió un juicio de

115 Para las discusiones de los constituyentes sobre las reformas del artículo 27 de 1917 véase, entre otros, RovaIx, Génesis de los artículos 27 y 123.

116 Autores que concuerdan con la idea de que le Suprema Corte apoyó incondicionalmente al Ejecutivo en cuanto a las cuestiones agrarias por lo menos hasta 1924 incluyen a Cabrera Acevedo, La Suprema... años constitucionalistas, t. I, p. 40; JAMEs, Revolución social, pp. 57-89, y Kuntz, La Reforma Agraria, pp. 3-29. 
amparo contra el delegado de la Comisión Nacional Agraria, el gobernador y la Comisión Local Agraria de Tlaxcala por haber ordenado la restitución al pueblo de San Cosme Xalostoc de terrenos presuntamente pertenecientes a la hacienda Tochac. El abogado de Sesma arguyó que este procedimiento violaba los artículos 14 y 16 de la Constitución, los cuales garantizaban que nadie podía ser privado de sus propiedades sin previa notificación y mediante juicio seguido ante los tribunales previamente establecidos. El juez de distrito de Tlaxcala mandó suspender el acto reclamado, pero la Suprema Corte unánimemente revocó el auto, citando la fracción VII del artículo 27 constitucional, la cual disponía "que todas las leyes de restitución son de inmediata ejecución por autoridad administrativa”. ${ }^{117}$ Los ministros lo justificaron argumentando que la autoridad administrativa y no la judicial tenía jurisdicción sobre las restituciones, ya que la ley de 6 de enero de 1915 era "de interés social y de orden público porque tiende a resolver uno de los problemas más trascendentales para el país: el problema agrario". ${ }^{118}$

Ya para febrero de 1919, la Suprema Corte había establecido la firme jurisprudencia de que los procedimientos que se basaban en la ley de 6 de enero de 1915 "deben hacerse por las autoridades administrativas y no por las judiciales". ${ }^{119}$ Por ejemplo, en el amparo del representante

117 Semanario Judicial, época 5, t. 1, pp. 400-403 (2 oct. 1917). Véase también Semanario Judicial, época 5, t. 1, pp. 945-946 (29 dic. 1917), y Semanario Judicial, época 5, t. 2, pp. 963-965 (21 mar. 1918).

118 Semanario Judicial, época 5, t. 1, pp. 400-403 (2 oct. 1917). Véase también James, Mexico's Supreme Court, p. 80.

119 Semanario Judicial, época 5, t. 4, pp. $402-407$ (15 feb. 1919). 
del pueblo de Xochimilco, Facundo Olivares, la Suprema Corte fundamentó que:

Conforme a la ley de 6 de enero de 1915, que tiene el carácter de constitucional, la dotación y la restitución de ejidos a los pueblos y comunidades debe hacerse administrativamente, pronunciando la última palabra en tales asuntos el Presidente de la República [...] Las resoluciones presidenciales [...] tienen el carácter de resoluciones judiciales. La solicitud respectiva es una verdadera demanda y los procedimientos seguidos, conforme a la ley de enero de 1915, constituyen un verdadero juicio, siendo la resolución que se dicte, una verdadera sentencia. ${ }^{120}$

El Poder Ejecutivo no sólo expandió su esfera administrativa, sino que se convirtió en un verdadero tribunal. En 1923, Lucio Mendieta y Núñez equiparó los procedimientos agrarios con los de un proceso judicial. Explicó que, como todo juicio, el agrario también tenía etapas:

Se establece como principio de todo procedimiento agrario una solicitud que viene a ser la demanda inicial del juicio. Se corre traslado de la solicitud a los propietarios afectados, haciéndoseles saber la instauración de la misma por medio de publicaciones [...] De este modo, aun cuando no precisamente en la forma clásica del juicio, se conservaron en el procedimiento agrario las formalidades esenciales a que se refiere el artículo 14 de la Constitución que dice que nadie puede ser privado de sus propiedades sino mediante un juicio seguido ante un juzgado. ${ }^{121}$

120 Semanario Judicial, época 5, t. 5, pp. 649-668 (15 oct. 1919).

121 Mendieta y Núñez, El problema agrario, p. 190. 
En efecto, la Comisión Nacional Agraria funcionaba como tribunal, como se puede observar en la siguiente resolución de la Suprema Corte. Cuando la administración agraria expropió terrenos para la dotación del pueblo de Santa Inés Zacatelco, Tlaxcala, los afectados denunciaron no haber sido parte de la tramitación del expediente de Zacatelco y que "la primera noticia que tuvieron fue la notificación del fallo presidencial". ${ }^{122} \mathrm{El}$ abogado argumentó que se violaban las garantías individuales de sus poderdantes porque "los quejosos no han sido oídos durante la tramitación del expediente, ni siquiera fueron citados en él, lo que hace que se les prive de sus propiedades y derechos sin que medie juicio en que se cumplan las formalidades del procedimiento". ${ }^{123} \mathrm{En}$ este caso, la Suprema Corte amparó a los quejosos porque,

[...] como las solicitudes son unas verdaderas demandas, los procedimientos constituyen un verdadero juicio, y la resolución definitiva goza de la naturaleza de una sentencia y mediante ella se priva a los terratenientes de sus propiedades, posesiones y derechos, es indudable que para que esa expropiación no pueda considerarse como ilegal, debe hacerse conocer la solicitud a los probablemente afectados con dicha expropiación, para que conociéndola puedan hacer uso de todos los medios de defensa que la ley concede. ${ }^{124}$

Otra manera en que la reforma agraria carrancista alteró la división de poderes decimonónica, fortaleciendo al Poder Ejecutivo a costa del Judicial, fue creando nuevas normas

122 ACSCJN, exp. 104 (1924), en Kuntz, La Reforma Agraria, pp. 55.

123 ACSCJN, exp. 104 (1924), en KunTz, La Reforma Agraria, pp. 55-56.

124 ACSCJN, exp. 104 (1924), en Kuntz, La Reforma Agraria, p. 62. 
para las expropiaciones agrarias. Durante el porfiriato había dos reglas fundamentales: primero, toda expropiación debía ser por causa de utilidad pública y debía ser transferida a un órgano del Estado (ya fuera la federación, las entidades federales o los ayuntamientos); segundo, la expropiación sólo se podía hacer con previa indemnización. ${ }^{125}$ Las primeras dos supremas cortes revolucionarias (1917-1923) siguieron muy estrictamente estos preceptos en los casos de expropiaciones no agrarias. ${ }^{126}$ Sin embargo, en el caso de las dotaciones, los ministros ayudaron a concebir una nueva forma de expropiación en cuanto al significado de la utilidad pública y el requerimiento de la previa indemnización. En efecto, en el amparo de Julio Luján en contra de actos de la legislatura y el gobierno de Durango, los magistrados resolvieron que "la Constitución Federal vigente, en su artículo veintisiete, establece principios generales para la expropiación $y$ reglas especiales para los casos en que ésta tiene por objeto la solución del problema agrario". ${ }^{127}$

Por "utilidad pública en cuestiones agrarias" debía entenderse "lo que satisface una necesidad pública y redunda en beneficio de la colectividad, siendo esencial que la cosa expropiada pase a ser del goce y de la propiedad de la comunidad y no de simples individuos". 128 "La comunidad" eran las poblaciones rurales con categoría política (villas, pueblos, rancherías, entre otras) que carecían de tierras y

\footnotetext{
Véase también James, Revolución social, p. 63.

${ }^{126}$ Herrera-Martin, “Judicial Review of Expropriation”, pp. 148-149.

127 Semanario Judicial, época 5, t. 4, p. 918 (29 abr. 1919). Cursivas de la autora.

128 Semanario Judicial, época 5, t. 4, p. 919.
} 
aguas. ${ }^{129}$ Sin embargo, en las expropiaciones agrarias el Ejecutivo no transfería la propiedad privada a un órgano del Estado, como el ayuntamiento, sino que la transfería a los comités particulares administrativos - arreglos institucionales carrancistas, creados para los manejos de los bienes comunales - mientras se reglamentaban las leyes federales en la materia. ${ }^{130}$

En cuanto a la indemnización, la Suprema Corte permitió la expropiación de tierras y aguas privadas sin previa compensación para dotar a los pueblos necesitados. Por ejemplo, en el amparo promovido por Rafael de Salcedo y Echave en contra de la expropiación de su propiedad para la dotación de tierras al pueblo de San Pedro Totoltepec (Estado de México), los ministros de la Corte consideraron que

[...] el Ejecutivo está facultado por la Constitución para decretar expropiación de la propiedad privada a fin de dotar de tierras a los pueblos, discrecionalmente, sin más restricción que el respeto a la pequeña propiedad, no teniendo los propietarios expropiados más derecho que el de [posteriormente] exigir la indemnización correspondiente. ${ }^{131}$

La Suprema Corte no sólo justificó los poderes extraordinarios del Ejecutivo en materia agraria, sino que también redujo la autoridad del Poder Judicial al prohibir la

129 “Artículo 27 de la Constitución de 1917”, en Fabila, Cinco siglos, pp. 261-264.

${ }_{130}$ Para los comités particulares agrarios, véase la circular núm. 22 de la Comisión Nacional Agraria (18 de abril de 1916), en Fabila, Cinco siglos, pp. 272-273, y BaITENMANN, “El que parte y reparte”.

131 Semanario Judicial, época 5, t. 2, p. 1053 (3 abr. 1918). 
inmediata suspensión de un acto por los Juzgados de Distrito - poder que tenían los jueces de distrito en todos los demás asuntos. ${ }^{132}$ Ya en la sentencia de 1917, en el amparo promovido por Elena Sesma en Tlaxcala, la Suprema Corte falló que "la inejecución de resoluciones fundadas en la misma ley, afecta directamente y causa perjuicio al Estado y a la sociedad". ${ }^{133}$ Ese mismo año, en el amparo promovido por la familia Sada en contra de la expropiación de su propiedad para la dotación de tierras al pueblo de Nazareno Etla, Oaxaca, la Suprema Corte argumentó que

[...] de concederse la suspensión, se seguían perjuicios a la sociedad, en cuyo beneficio y para satisfacer necesidades de orden político, se dictaron las medidas y disposiciones contenidas en la Ley Agraria de seis de enero de mil novecientos quince, elevada a Ley Constitucional, como lo declara el artículo 27 de la Constitución. ${ }^{134}$

Una forma más en que los ministros de la Suprema Corte redujeron la autoridad del Poder Judicial en materia agraria era pasando por alto el derecho a ser oído del artículo 10 de la ley de 6 de enero de 1915. Este artículo establecía que "los interesados que se creyeren perjudicados con la resolución del encargado del Poder Ejecutivo de la Nación, podrán ocurrir ante los tribunales a deducir sus derechos dentro del término de un año". ${ }^{135} \mathrm{Y}$, sin embargo, ni la ley de 6 de enero

\footnotetext{
132 James, Revolución social, p. 63.

133 Semanario Judicial, época 5, t. 1, pp. 400-403 (2 oct. 1917).

134 Semanario Judicial, época 5, t. 1, pp. 945-946 (29 dic. 1917).

135 “Decreto de 6 de enero de 1915”, en Fabila, Cinco siglos, p. 231. También dispone que, "en los casos en que se reclame contra reivindicaciones
} 
de 1915 ni los subsecuentes reglamentos agrarios definieron el procedimiento judicial ordinario a favor de los afectados por las dotaciones o restituciones (ya fueran propietarios o pueblos). En efecto, según Cabrera Acevedo, "en realidad, nadie sabía a punto fijo cuál debería ser la naturaleza del juicio a que se refería la ley de 6 de enero de 1915, ni ante qué autoridades habría de intentarse ni en contra de quién". 136

La falta de procedimientos judiciales ordinarios significó que los afectados no tenían más recurso que el amparo: "La Suprema Corte de Justicia - explica Sandra Kuntz - era la única instancia judicial para corregir los errores que pudieran cometer los órganos administrativos (las comisiones locales, la Comisión Nacional Agraria, etc.) encargados de gestionar la redistribución de la propiedad agraria”. ${ }^{137}$ Más aún, los afectados de estos errores o violaciones de las nuevas leyes agrarias no sólo eran grandes propietarios, sino también beneficiarios del reparto. En un caso, por ejemplo, Victoriano Medina y los demás miembros del comité particular administrativo del pueblo de San Juan Ixtayopan, Xochimilco, obtuvieron la restitución de sus terrenos en 1917, pero en 1920 la Comisión Local Agraria del Distrito Federal les quitó una fracción presuntamente perteneciente a un pequeño propietario que no había podido comprobar su derecho en 1917 porque, "debido a la revolución, casi

\footnotetext{
y en que el interesado obtenga resolución judicial declarando que no procedía la restitución hecha a un pueblo, la sentencia sólo dará derecho a obtener del Gobierno de la Nación la indemnización correspondiente", p. 232.

136 Cabrera Acevedo, La Suprema ... años constitucionalistas, t. I, p. 38. 137 Kuntz, La Reforma Agraria, p. 27.
} 
todos los habitantes estaban fuera de sus hogares". ${ }^{138}$ Por falta de procedimientos judiciales ordinarios, tuvieron que pedir amparo contra actos del gobernador y de la Comisión Local Agraria del Distrito Federal. La Suprema Corte falló en favor del amparo, dejando sin valor la resolución del gobernador y de la comisión local "que quita a los quejosos una posesión que de hecho y derecho les corresponde”. ${ }^{139}$

La falta de un recurso judicial ordinario que convertía a la Suprema Corte en la única instancia judicial capaz de rectificar los abusos cometidos por las autoridades agrarias tarde o temprano la transformaría en un obstáculo para la reforma agraria - una historia compleja que aún falta por escribir con base en los expedientes de archivo.

\section{COMENTARIOS FINALES}

A lo largo del siglo xix, e incluso durante el porfiriato, el Poder Judicial defendió con éxito su autoridad sobre los asuntos contenciosos relacionados con las tierras de los pueblos. El objeto de este trabajo no ha sido valorar el desempeño de los juzgados decimonónicos (un tema muy amplio que aún falta por estudiar). Sin embargo, todo apunta a una evaluación más matizada de la leyenda negra del porfiriato, la cual culpó al Poder Judicial de la pérdida de las tierras de los pueblos durante el siglo xix. Un clásico ejemplo de esta narrativa es el preámbulo a las reformas del artículo 27 constitucional en 1931, que limitaban aún más el papel de este poder en cuestiones agrarias. Allí, los funcionarios

138 Semanario Judicial, época 5, t. 10, p. 770 (6 abr. 1922).

139 Semanario Judicial, época 5, t. 10, p. 771. 
explicaban que, durante los cien años de vida independiente de la República

[...] en todos los juicios que los pueblos llevaban ante los tribunales para defender sus derechos, aquéllos obtenían en un crecido porcentaje, indefectiblemente, sentencias que los condenaban a perder sus tierras. Esto como consecuencia de la influencia predominante y decisiva que ejercían los terratenientes en tiempos de la dictadura. ${ }^{140}$

Este artículo ha demostrado que cuando los representantes de los pueblos no lograban la reivindicación de sus tierras era por razones más complicadas. Muchas veces el problema fue la incompatibilidad de los diferentes sistemas de propiedad y la pesada carga de la prueba del demandante. Durante y después de la presidencia del ministro Vallarta en la Suprema Corte, la justicia fue indiscutiblemente parcial, al negarles a los representantes de los pueblos la capacidad jurídica para ser sujetos de una relación procesal y así defender sus tierras comunales. Por esta y otras razones (como lo costosos y lo tardados que resultaban los juicios), los representantes de los pueblos solían pedir al Ejecutivo la resolución de sus disputas fuera de los tribunales y, en respuesta, un número de gobernadores intentaron encontrar soluciones administrativas a los juicios de reivindicación y a los de apeo y deslinde de las tierras de los pueblos. Sin embargo, el Poder Judicial defendió con exito su jurisdicción sobre asuntos contenciosos.

140 Preámbulo al decreto que reforma el artículo 10 de la Ley Agraria de 6 de enero de 1915 (el decreto es de 15 de enero de 1932), en ACSCJN, exp. 246. 
Esta fue la situación cuando Madero prometió en sus circulares de 1912 subsanar las quejas de los pueblos "dentro de su esfera de acción administrativa”. ${ }^{141}$ Así como los representantes de los pueblos habían tenido un papel clave durante el siglo XIX en presionar al Ejecutivo para que se hiciera cargo de la justicia, decenas de ellos enviaron peticiones y comisiones a las oficinas de gobierno pidiendo soluciones a sus contiendas por la vía administrativa. A pesar de que Madero no tenía la intención de reajustar la competencia del Poder Ejecutivo, los apoderados de los pueblos aprovecharon estas circulares para hacer una serie de peticiones, entre ellas el apeo y deslinde de las tierras de los pueblos (y su posterior privatización) como estrategia de reivindicación de los terrenos presuntamente usurpados. Sin embargo, se encontraron con que los jueces de distrito y los ministros de la Suprema Corte fallaron en contra de los deslindes al proteger el derecho constitucional de las partes a ser oídas ante autoridades judiciales competentes.

No fue sino hasta principios de 1915, en medio de una guerra civil y con el Poder Judicial clausurado, que Carranza accedió a firmar un decreto agrario redactado esencialmente para resolver el problema de la reivindicación de las tierras de los pueblos. Este decreto fue en verdad revolucionario, en el sentido de alterar el orden político existente, porque cambió el equilibrio de poder decimonónico.

Este cambio en la distribución de poderes fue bien recibido por varios sectores, incluyendo a los representantes de los pueblos, que aprovechaban las promesas del nuevo Poder Ejecutivo para tratar de solucionar una variedad de

${ }^{141}$ Circular del 17 de febrero de 1912, en Colección de leyes sobre tierras, pp. 172-174. 
litigios pendientes; los constituyentes de 1916-1917, quienes incorporaron los poderes especiales del Ejecutivo en el artículo 27, y los ministros de las primeras dos supremas cortes, quienes justificaron y ratificaron estos poderes ejecutivos excepcionales.

Las consecuencias del poder sui generis del Ejecutivo en materia agraria fueron profundas por dos razones. Primero, porque el Ejecutivo no sólo adquirió facultades judiciales para fallar en casos restitutorios y dotatorios, sino también para resolver diferentes tipos de litigios que aumentaron con el tiempo. Éstos incluían el poder de reconocer o confirmar los terrenos comunales existentes y marcar sus límites con otros pueblos o particulares; las controversias por límites de terrenos entre dos o más núcleos de población ejidal o comunal, y de éstos con pequeños propietarios; las controversias en materia agraria entre ejidatarios, comuneros o avecindados, y las controversias relativas a la sucesión de derechos ejidales y comunales, entre muchas otras funciones. Esto significa que no sólo los grandes terratenientes, sino también los pequeños propietarios, así como miles de ejidatarios y comuneros, perdieron el derecho constitucional a un juicio ante autoridad competente. Y segundo, la administración agraria no se daba abasto, dejando miles de expedientes sin resolver - un fenómeno conocido como "el rezago agrario". ${ }^{142}$ No fue sino hasta la reforma constitucional de 1992, con la instauración de los tribunales agrarios, que los funcionarios y los académicos se empezaron a

${ }^{142}$ En su primer año y medio, los tribunales unitarios recibieron más de 20000 asuntos, que por la temprana fecha se pueden considerar parte del rezago del viejo sistema. Martínez Guerrero, "Tribunales agrarios”, p. 179. 
percatar de lo que significaron más de siete décadas en las que el Ejecutivo fue juez y parte del mismo proceso.

\section{SIGLAS Y REFERENCIAS}

ACSCJN Archivo Central de la Suprema Corte de Justicia de la Nación, Ciudad de México.

AGA Archivo General Agrario, Ciudad de México.

AGN, G-leg Archivo General de la Nación, fondo Gobernación-legajos, Ciudad de México.

AGN, GPR Archivo General de la Nación, fondo Gobernación Periodo Revolucionario, Ciudad de México.

AGN, Gs/s Archivo General de la Nación, fondo Gobernación, sin sección, Ciudad de México.

AGN, JPCM Archivo General de la Nación, fondo Junta Protectora de las Clases Menesterosas, Ciudad de México.

AGN, SJ Archivo General de la Nación, fondo Secretaría de Justicia, Ciudad de México.

AGN, $M$ Archivo General de la Nación, fondo Madero, Ciudad de México.

AGN, SAF-CNA Archivo General de la Nación, fondo Secretaría de Agricultura y Fomento, Comisión $\mathrm{Na}$ cional Agraria, Ciudad de México.

AHUNAM, $A G M, L B$ Archivo Histórico de la Universidad Nacional Autónoma de México, Archivo Gildardo y Octavio Magaña Cerda-fondo León de la Barra, Ciudad de México.

Actas del Congreso del Estado de México

Actas del Congreso del Estado de México revisadas por el mismo Congreso e impresas a su orden, Toluca, Imprenta a cargo de Martín Rivera, 1824.

Arrioja Díaz Viruell, Luis Alberto

"Conflictos por tierras y pesquisas documentales en el Valle de Oaxaca, 1912”, en Arrioja Díaz Viruell y Sánchez SilvA (coords.), 2012. 
Arrioja Díaz Viruell, Luis Alberto y Carlos Sánchez Silva (coords.)

Conflictos por la tierra en Oaxaca: de las reformas borbónicas a la reforma agraria, Zamora, El Colegio de Michoacán, Universidad Autónoma “Benito Juárez” de Oaxaca, 2012.

Ávila Espinosa, Felipe Arturo

Los orígenes del zapatismo, México, El Colegio de México, 2001.

Baitenmann, Helga

"El que parte y reparte... Los arreglos institucionales locales a cargo de los repartos agrarios (siglo xix-1927)”, en EscOBAR Ohmstede (coord.) [en prensa].

Barrera, Florencio y Claudio Barrera

"La falsificación de títulos de tierras a principios del siglo xx", en Historias, 72 (2009), pp. 41-63.

Birrichaga Gardida, Diana

"Administración de tierras y bienes comunales. Política, organización territorial y comunidad de los pueblos de Texcoco, 1812-1857”, tesis de doctorado en historia, México, El Colegio de México, 2003.

BoraH, Woodrow

"La justificación del Juzgado General de Indios (1595-1603)", en Memoria del II Congreso de Historia del Derecho Mexicano (1980), México, Universidad Nacional Autónoma de México, 1981, pp. 147-160.

Cabrera Acevedo, Lucio

La Suprema Corte de Justicia en La República Restaurada (1867-1876), México, Suprema Corte de Justicia de la Nación, 1989.

La Suprema Corte de Justicia a principios del siglo XX (19011914), México, Suprema Corte de Justicia de la Nación, 1993. 
La Suprema Corte de Justicia durante los años constitucionalistas (1917-1920), México, Suprema Corte de Justicia de la Nación, 1995, t. I.

Cabrera Acevedo, Lucio (coord.)

La Suprema Corte de Justicia en el primer periodo del porfirismo (1877-1882), México, Suprema Corte de Justicia de la Nación, 1990.

Chávez Padrón, Martha

Elproceso social agrario y sus procedimientos, México, Porrúa, 1971.

El derecho procesal social agrario, México, Porrúa, 2003.

Colección de acuerdos, órdenes y decretos

Colección de acuerdos, órdenes y decretos, sobre tierras, casas $y$ solares de los indigenas, bienes de sus comunidades y fundos legales de Jalisco, Guadalajara, Imprenta del Gobierno del Estado, 1849 , vol. I.

Colección de acuerdos, órdenes y decretos, sobre tierras, casas $y$ solares de los indígenas, bienes de sus comunidades y fundos legales de Jalisco, Guadalajara, Tipografía de J. M. Brambila, 1868 , vol. III.

Colección de leyes sobre tierras

Colección de leyes sobre tierras y disposiciones sobre ejidos publicada por orden de la Secretaría de Fomento, México, Imprenta y Fototipia de la Secretaría de Fomento, 1913.

Escobar Ohmstede, Antonio (coord.)

El mundo rural mexicano en la transición del siglo XIX al siglo $X X$, México, Centro de Investigaciones y Estudios Superiores en Antropología Social, El Colegio de Sonora, El Colegio de San Luis [en prensa].

Fabila, Manuel

Cinco siglos de legislación agraria (1493-1940), México, Secre- 
taría de la Reforma Agraria y Centro de Estudios Históricos del Agrarismo en México, 1990.

FALCón, Romana

"Litigios interminables. Indígenas y comuneros ante la justicia agraria liberal (1857-1928)”, en MANDRINi, Escobar OHMsTEDE, y ORTELLI (coords.), 2007, pp. 81-97.

"El arte de la petición: rituales de obediencia y negociación, México, segunda mitad del siglo xix", en The Hispanic American Historical Review, 86: 3 (2006), pp. 467-500.

El jefe político: un dominio negociado en el mundo rural del Estado de México, 1856-1911, México, El Colegio de México, El Colegio de Michoacán, Centro de Investigaciones y Estudios Superiores en Antropología Social, 2015.

Fenner, Julius

"Pérdida o permanencia: el acaparamiento de las tierras colectivas en Chiapas durante el porfiriato. Un acercamiento a la problemática desde los expedientes del Juzgado de Distrito (1876-1910)", en Revista Pueblos y Fronteras digital, 3 (2007), s.p.

García Ramírez, Sergio

"Establecimiento y horizonte de la jurisdicción agraria en México", en Revista de los Tribunales Agrarios, 57 (2012), pp. 1-61.

González Navarro, Moisés

"Vallarta, indios y extranjeros en la Suprema Corte de Justicia de la Nación (1877-1887)”, en Cabrera Acevedo (coord.), 1990, pp. 1075-1090.

González Roa, Fernando

Parte general de un informe sobre la aplicación de algunos preceptos de la Ley Agraria de 6 de enero de 1915, México, Secretaría de Fomento, 1916.

El aspecto agrario de la Revolución mexicana, México, Dirección de Talleres Gráficos, 1919. 
Hernández Chávez, Alicia

Anenecuilco: Memoria y vida de un pueblo, México, El Colegio de México, 1991.

Herrera-Martin, Carlos Reynaldo

"Judicial Review of Expropriation: The case of Mexico", tesis de doctorado en leyes, Londres, University College London, 2014.

Holden, Robert H.

"Priorities of the State in the Survey of the Public Land in Mexico, 1876-1911", en The Hispanic American Historical Review, $70: 4$ (1990), pp. 579-608.

Irurozqui, Marta y Miriam Galante (cords.)

Sangre de ley: justicia y violencia en la institucionalizacion del Estado en América Latina, siglo XIX, Madrid, Polifemo, 2011.

James, Timothy M.

Revolución social e interpretación constitucional: la Suprema Corte y la reforma social revolucionaria, 1916-1934, México, Suprema Corte de Justicia de la Nación, 2010.

Mexico's Supreme Court: Between Liberal Individual and Revolutionary Social Rights, 1867-1934, Albuquerque, University of New Mexico Press, 2013.

Knowlton, Robert J.

"La división de las tierras de los pueblos durante el siglo xIx: el caso de Michoacán”, en Historia Mexicana, xL:1 (109) (jul.sep. 1990), pp. 3-25.

“Tribunales federales y terrenos rurales en el México del siglo xIx; el Semanario judicial de la Federación, en Historia Mexicana, Xlvi:1 (181) (jul.-sep. 1996), pp. 71-98.

Kourí, Emilio

"Los pueblos y sus tierras en el México porfiriano: un legado 
inexplorado de Andrés Molina Enríquez”, en Kourí (coord.), 2009, pp. 253-330.

Kourí, Emilio (coord.)

En busca de Molina Enríquez. Cien años de Los grandes problemas nacionales, México, El Colegio de México, Centro Katz-The University of Chicago, 2009.

Kuntz Ficker, Sandra

La Reforma Agraria durante los años veinte en los expedientes de la Suprema Corte de Justicia de la Nación, México, Suprema Corte de Justicia de la Nación, 2012.

Ley expedida por el Gobierno del Estado de Michoacán

Ley expedida por el Gobierno del Estado de Michoacán en 15 de setiembre [sic] de 1859, para terminar los negocios de indígenas sobre tierras, Morelia, 1859.

Mallon, Florencia E.

Peasant and Nation: The Making of Postcolonial Mexico and Peru, Berkeley, University of California Press, 1995.

Mandrini Raúl J., Antonio Escobar Ohmstede y Sara Ortelli (coords.)

Sociedades en movimiento: los pueblos indígenas de América Latina en el siglo XIX, Tandil, Argentina, Instituto de Estudios Históricos Sociales, 2007.

Marino, Daniela

"Buscando su lugar en el mundo del derecho: actores colectivos, reforma y jurisprudencia”, en Pampillo Baliño y WieCHERS Veloz (coords.), 2005, pp. 235-262.

"La modernidad a juicio: los pueblos de Huixquilucan en la transición jurídica (Estado de México, 1856-1911)", tesis de doctorado en historia, México, El Colegio de México, 2006. 
"La fuerza de la ley: leyes, justicias y resistencias en la imposición de la propiedad privada en México, segunda mitad del siglo xix”, en IrurozQui y GaLANTe (coords.), 2011, pp. 203-234.

“'La medida de su existencia'. La abolición de las comunidades indígenas y el juicio de amparo en el contexto desamortizador (Centro de México, 1856-1910)", en Revista de Indias, LXXvi: 266 (2016), pp. 287-313.

Martínez Guerrero, Marco Vinicio

“Tribunales agrarios a veinte años de su creación”, en Estudios Agrarios, 50 (2012), pp. 169-193.

Mendieta y Núñez, Lucio

El problema agrario de México desde su origen hasta la época actual, México, s.e., 1923.

Molina Enríquez, Andrés

Los grandes problemas nacionales, México, Ediciones Era, 1978.

Neri Guarneros, Porfirio

"Sociedades agrícolas en resistencia. Los pueblos de San Miguel, Santa Cruz y San Pedro, 1878-1883”, en Historia Crítica, 51 (2013), pp. 21-44.

OrTIZ YAM, Isaura Inés

"Formación de ejidos en los pueblos de Yucatán, 1870-1909", en Temas Antropológicos. Revista Científica de Investigaciones Regionales, 36: 2 (2014), pp. 17-41.

Pampillo Baliño y Wiechers Veloz (coords.)

Historia de la justicia en México, México, Suprema Corte de Justicia de la Nación, 2005, vol. 1.

Purnell, Jennie

"Citizens and Sons of the Pueblo: National and Local Identities in the Making of the Mexican nation", en Ethnic and Racial Studies, 25: 2 (2010), pp. 213-237. 
Romero Frizzi, María de los Ángeles

"Conflictos agrarios, historia y peritajes paleográficos. Reflexionando desde Oaxaca”, en Estudios Agrarios, 17: 47 (2011), pp. 65-81.

Rouaix, Pastor

Génesis de los artículos 27 y 123 de la Constitución Política de 1917, México, Instituto Nacional de Estudios Históricos de la Revolución Mexicana, 1959.

Secretaría de Fomento

Ley de Tierras de 26 de marzo de 1894 y sus reglamentos, México, Tipografía de la Secretaría de Fomento, 1896.

Memoria de la Secretaría de Fomento presentada al Congreso de la Unión por el secretario de estado y del despacho del ramo Alberto Robles Gil, correspondiente al ejercicio fiscal 19111912, México, Secretaría de Fomento, 1913.

Secretaría de la Reforma Agraria y Secretaría de la PresiDENCIA

México a través de los informes presidenciales: la política agraria, México, Secretaría de la Presidencia, 1976.

Silva Herzog, Jesús (comp.)

La cuestión de la tierra, México, Instituto Mexicano de Investigaciones Económicas, 1961, vol. II.

UlloA, Berta

Historia de la Revolución mexicana 1914-1917, vol. 6, La Constitución de 1917, México, El Colegio de México, 2005.

ZÁrate H., J. Eduardo

"Comunidad, reformas liberales y emergencia del indígena moderno. Pueblos de la Meseta Purépecha (1864-1904)", en Relaciones, 32: 115 (2011), pp. 17-52. 